\title{
Heat Flow near Major Strike-Slip Faults in California ${ }^{1}$
}

\author{
T. I. HENYEY ${ }^{2}$ AND G. J. WASSERBURG \\ Division of Geological and Planetary Sciences \\ California Institute of Technology, Pasadena 91109
}

\begin{abstract}
Seventeen heat-flow measurements were made in crystalline rock near the San Andreas, San Jacinto, and Garlock faults, California, in regions representative of several levels of seismic activity. Data from these measurements, together with other heat-flow determinations in California and offshore along the continental borderland, do not clearly demonstrate the existence of a heat-flow anomaly in the vicinity of these major faults, although regularities in the data are present. The mean value of the seventeen determinations is $1.65 \mu \mathrm{cal} / \mathrm{cm}^{2} / \mathrm{sec}, \pm 0.28 \mathrm{s.d}$. It is concluded that any or all of the following are the case: $(a)$ the amount of energy converted to heat near a fault is no larger than that appearing as seismic waves; $(b)$ the presently inferred rates of slip on the faults studied have been going on for only the last few million years or less; (c) the high density of fault systems in central and southern California contributes to a regionally high heat flow but prevents the resolution of energy from any single member; $(d)$ the frictional heat generation varies from place to place along the faults. In the region between Lake Hughes and San Bernardino, now seismically inactive, but in the zone of rupture from the $\sim 8$-magnitude Fort Tejon earthquake, six measurements show no correlation with distance from the San Andreas fault. Near the San Jacinto fault in the Peninsular Ranges, a region characterized by frequent intermediate- and low-magnitude earthquakes, determinations at 1 and $4 \mathrm{~km}$ from the fault are the same; they are $20 \%$ higher than a measurement $13 \mathrm{~km}$ to the west but are not appreciably different from a probable regional average $25 \mathrm{~km}$ to the east in the Imperial Valley. Near Hollister, where the San Andreas fault is creeping at a rate of several centimeters per year, a measurement $3 \mathrm{~km}$ west of the fault gives a value similar to those found elsewhere along the fault, yet significantly higher than values to the east on the western flank of the Sierra Nevada. Finally, measurements across the historically inactive Garlock fault exhibit high fluxes near the fault in comparison with a determination $8 \mathrm{~km}$ to the north, but these measurements are only slightly higher than values characteristic of the Mojave block to the south.
\end{abstract}

Prior to 1964, only three heat-flow measurements had been reported in California, namely, those of Benfield [1947] "west of Bakersfield, Clark [1957] at Grass Valley, and Roy [1963] near Barstow. California, which occupies a region of critical tectonic significance, was sorely in need of additional geothermal data. In 1964 three organizations, Caltech, Harvard, and the U.S. Geological Survey, began heat-flow programs, which have led to perhaps 50 heat-flow determinations at present throughout California. In addition, the continental data have been sup-

${ }^{1}$ Contribution 1932 of the Division of Geological and Planetary Sciences, California Institute of Technology, Pasadena 91109.

2 Now at the Department of Geological Sciences, University of Southern California, Los Angeles 90007.

Copyright (C) 1971 by the American Geophysical Union. plemented by a similar quantity of nearshore oceanic measurements.

An experiment to measure heat flow in the vicinity of major strike-slip faults was begun in 1965 , since near seismically active faults a significant amount of strain energy might be converted to heat by means of dissipative processes operating during fault slippage. Calculations based on the Gutenberg-Richter seismic energyearthquake magnitude relation and the probable occurrence of two 8-magnitude earthquakes per century along the length of the San Andreas fault suggested that if the amount of energy converted to heat was at least as great as that appearing as seismic waves [Bullard, 1954], and depending on fault geometry, a measurable heatflow anomaly could exist near the trace of a major fault. The existence or nonexistence of a measurable heat-flow anomaly associated with large faults permits limits to be set on the average frictional stresses acting across fault planes 
[Orowan, 1960]. This result, together with earthquake energy-magnitude relations, can provide information regarding the efficiency of seismicwave generation [King and Knopoff, 1968].

The field program of heat-flow studies begun in 1965 explored the San Andreas and related faults (see Figure 1). Drilling sites were chosen in several regions having different types of seismic activity and geologic terrane. Although selection of sites on this basis reduced the density of heat-flow measurements, the investigation of several regions along the fault permitted comparison of independent sets of data.

Geologic and topographic irregularities near active faults greatly complicate the analysis of geothermal data. Generally the topography is rugged, and rocks of dissimilar lithologies are juxtaposed. Hot springs are common in seismically active areas [Stearns et al., 1937], and the local rock is usually fractured and decomposed even at depth. Areas of crystalline outcrop were sought for drill sites, preferably occurring on both sides of the fault to minimize the effect of refraction of heat; the sites were chosen on the basis of existing geologic maps [see, e.g., Sharp,
1967; Dibblee, 1961; Wiese, 1950]. It was found that holes drilled in the fractured and decomposed rock within $1 \mathrm{~km}$ of the fault yielded uniform gradients and satisfactory heat-flow results. Problems encountered at the sites were associated primarily with the drilling operations.

The problem of investigating heat flow in relation to a major fault is somewhat ambiguous. First, observations suggest that at the surface motions have occurred throughout a zone that may be anywhere from a few hundred feet to more than a mile wide [Oakeshott, 1966]; extensive fracturing of the rocks occurs out to several kilometers on either side of the mapped fault trace. En echelon faults and fault branches that now appear inactive may have been responsible for much of the displacement in the past. In addition, hypocenter locations do not define a single surface trace [California Department of Water Resources Bulletin, 1964; Allen et al., 1965], but rather suggest that for, say, a 10-km segment of fault, strain energy is being liberated throughout a volume of the order of $10^{8} \mathrm{~km}^{2}$ or larger. Second, in central and southern California, active faults occur every few tens of

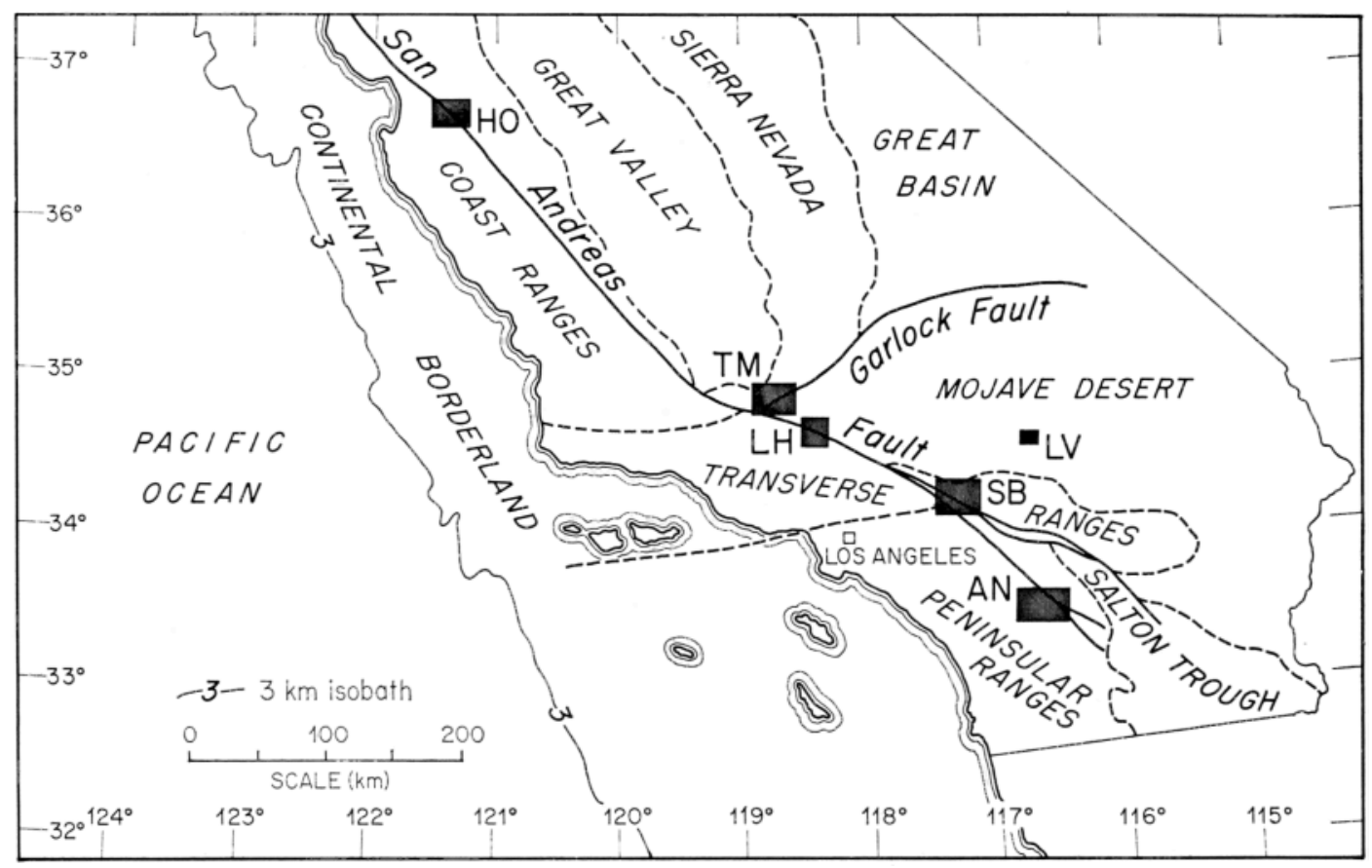

Fig. 1. Regions along the San Andreas fault system where heat-flow determinations for this study were made. HO, Hollister; TM, Tehachapi Mountains; LH, Lake Hughes; LV, Lucerne Valley; SB, San Bernardino Mountains; AN, Anza. 
kilometers apart, and thus 'base level' values of heat flow characteristic of large distances from a given fault are hard to determine. For these reasons, spatial considerations become important when interpreting the magnitude of an anomaly in terms of total energy release.

Localities were selected on the basis of seismic statistics and geologic studies defining fault zones that are now active. Owing to the thermal inertia of common crustal material, if, for example, we are to observe heat energy at the surface that has been generated along a fault at a depth of $10 \mathrm{~km}$, we must wait for a time of the order of one million years; the same pulse would not reach a distance of $50 \mathrm{~km}$ for 20 million years. Thus we should not expect to see the effect of a recent event on the fault, and we require millions of years of continuing activity for steady-state heat-flow conditions to prevail. Initial development of the San Andreas fault system is generally believed to have been preTertiary [Oakeshott, 1966] although recent evidence from the magnetic anomaly patterns off the western United States suggests that this fault system may not have developed until midor even late-Tertiary time [Atwater, 1970; $M c$ Kenzie and Morgan, 1969]. If motion along the San Andreas fault has been relatively uniform throughout Tertiary time, we can assume that steady-state conditions prevail in the vicinity of the fault. However, it is important to realize that we would not expect the same heat flows near a fault active for only the last one million years.

The field work and laboratory measurements for this study were carried out by the senior author during the period 1965-1967. Results reported in this work are complete and supersede those reported earlier by Wasserburg et al. [1966], Henyey et al. [1967], and Henyey [1968].

\section{Drilling and Hole Preparation}

All holes were cored using a diamond drill. Hole sizes were either $\mathrm{BX}(\sim 5$-cm hole and $3.8-\mathrm{cm}$ core) or $\mathrm{NX}(\sim 7.5-\mathrm{cm}$ hole and 5 -cm core), depending on the drilling circumstances. Total hole depths were in all cases greater than 200 meters, which was judged to be the minimum depth generally needed to obtain a reliable heatflow measurement. On completion of drilling, the hole was cased with $3.1-\mathrm{cm}$ iron pipe if there was any chance of caving. No holes were lost during the course of drilling, and all holes, including those nearest the fault zone, yielded useful data. In spite of the fact that the holes were drilled in areas adjacent to large, active faults, temperature disturbances due to circulating water were only encountered in those holes that intersected fracture zones in otherwise fresh rock, rather than in holes drilled in weathered and partially decomposed rock where the fractures were filled with silt and clay. Specific sites were chosen primarily on the basis of the existence of crystalline rock exposed adjacent to the fault and of subdued local topography (see Figure 2). Measurements were made soon after completion of the hole and at periods of time up to two years later to establish both temperature equilibrium and the reliability of the measurement obtained. This was particularly important for holes that encountered fracture zones, causing water loss during drilling, and thus yielding irregular initial temperature profiles. In all cases, fine-scale irregularities in the temperatures disappeared over the time period that the holes were monitored. Results of time-equilibration studies for one of the measured holes are given later.

All reported gradients were taken from temperatures measured below the local groundwater table, which ensured rapid equilibration of the temperature sensor with the environment. The reported temperatures were measured at least one year after drilling ceased. The detailed drilling characteristics and temperature studies for all holes reported here may be found in Henyey [1968].

\section{Temperature and Thermal Conductivity Measurements}

Temperatures were measured in the drill holes at discrete intervals (usually every 10 meters) with thermistors encased in a waterproof stainless-steel housing, in conjunction with a Wheatstone bridge compensated for lead-wire resistance [see Roy et al., 1968]. The probes were designed to function without loss of precision or physical integrity in the temperature range $0^{\circ}$ to $70^{\circ} \mathrm{C}$.

The thermistor probes were calibrated at $10^{\circ} \mathrm{C}$ intervals from $0^{\circ}$ to $60^{\circ} \mathrm{C}$ in our laboratory

Fig. 2. (Opposite) Generalized geologic maps of regions investigated along the San Andreas fault system, showing drill-hole locations and respective heat-flow values. 
ANZA
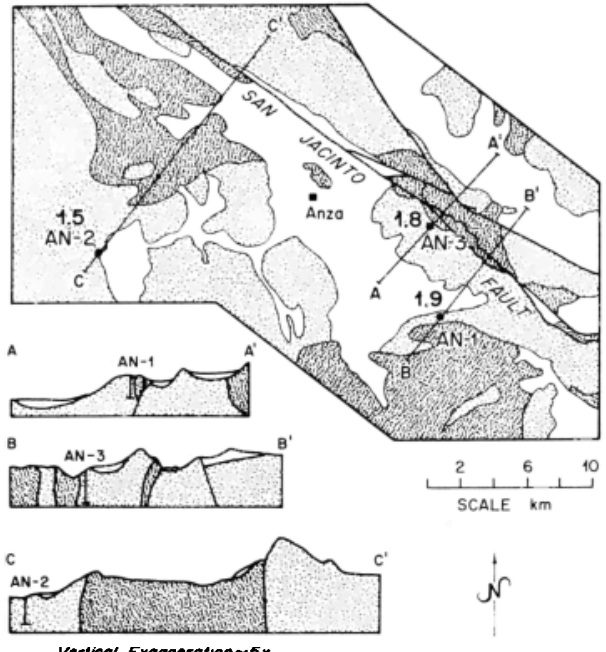

Verical Exaggoration 5x

\section{LAKE HUGHES}
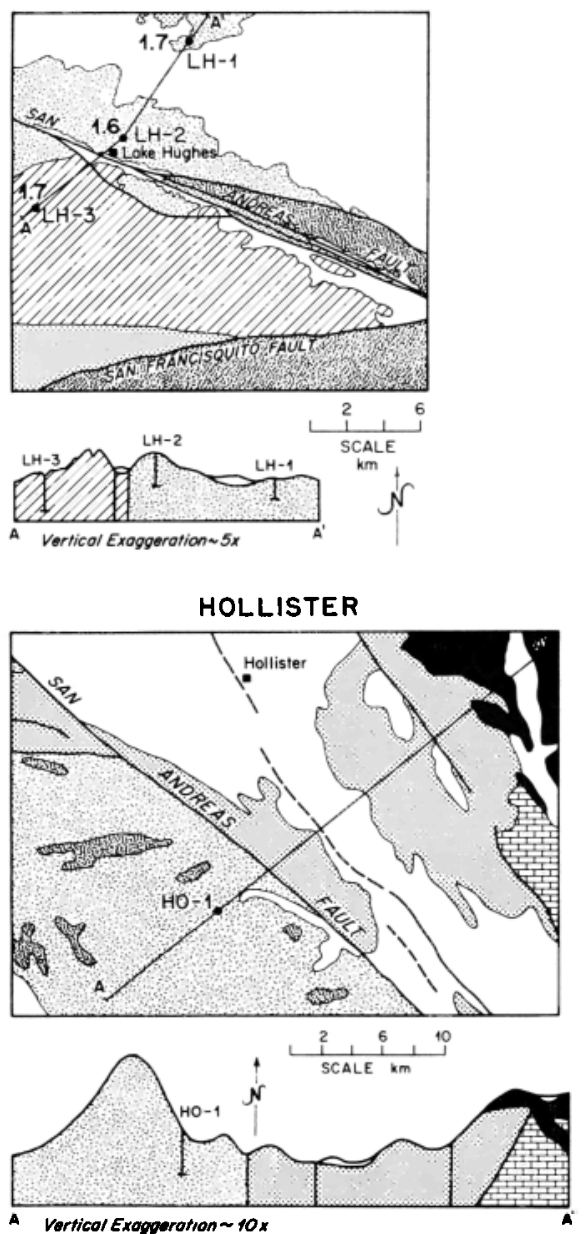

SAN BERNARDINO MTNS.

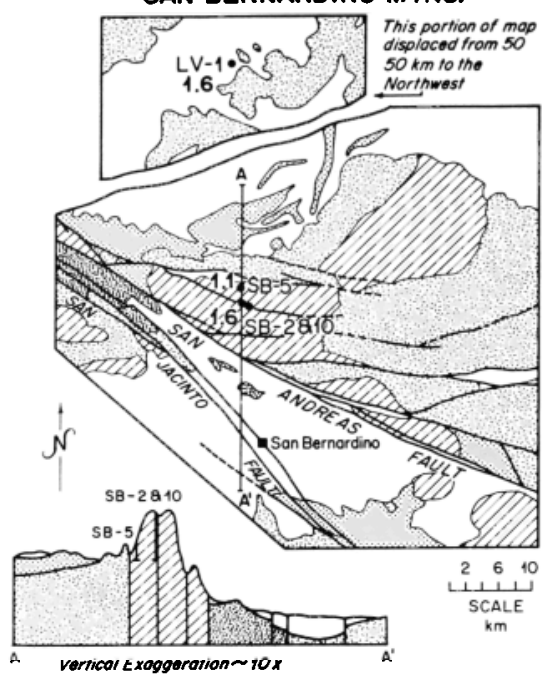

TEHACHAPI MOUNTAINS

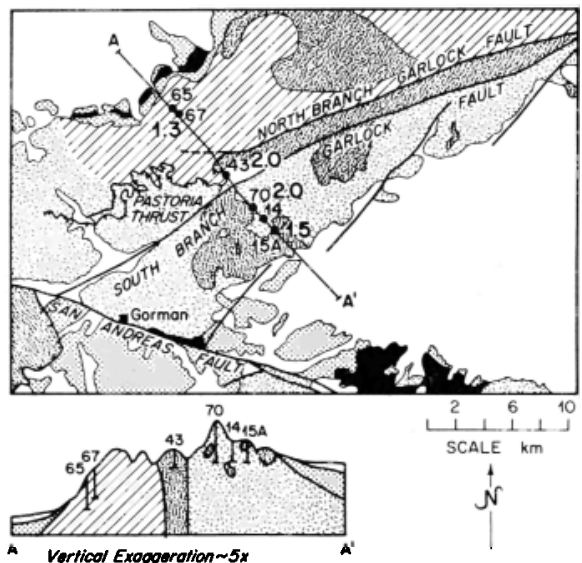

LEGEND

Quaternary Alluvium

Post-intrusive Upper Cretaceous and Tertiary Sedimentary Rocks

Tertiary Volcanic Rocks

Cretaceous (?) Franciscan Rocks

Mesozoic Plutonic Rocks

DIIT

Mesozolc (?) Gneissic Plutonic Rocks

Pre-intrusive Metamorphic Rocks

Fault

-LH-1 Drill Hole 
against a Leeds and Northrup $25-\Omega$ platinum resistance thermometer, together with an $L$ and $N$ K-3 potentiometer [Henyey, 1968]. The resistance $(R \Omega)$-temperature $\left(T^{\circ} \mathrm{K}\right)$ points were fitted with a second-order polynomial of the form

$$
\begin{array}{r}
\ln R=a+(b / T)+\left(c / T^{2}\right) \\
a, b, c \text { const }
\end{array}
$$

The total absolute accuracy of calibration is believed to be good to $\pm 0.05^{\circ} \mathrm{C}$, which, after smoothing by use of (1), should contribute errors of less than $\pm 0.2 \%$ to gradient determinations. Interlaboratory checks in stable holes with probes calibrated independently by Harvard University and the U.S. Geological Survey agreed within these limits. Cable leakage resistance and thermistor drift were found to be negligible.

Temperatures for all holes are given in Table 1. Interval gradients for all holes are plotted in Figures 3 and 4.

The thermal conductivity of individual 3.8cm-thick core disks was measured with the divided-bar apparatus similar to that described by Birch [1950] with modifications to help reduce side heat losses and thermal contact resistance [Roy et al., 1968]. Calibration of the divided bar was performed with a 3.8-cm combination of natural quartz (heat flow normal to optic axis) and silica glass having mean resistivity of about $180\left(\mathrm{~cm} \mathrm{sec}{ }^{\circ} \mathrm{C}\right) / \mathrm{cal}$, approximately equivalent to an average rock. Ratcliffe's [1959] absolute values for the conductivity of quartz and silica glass were used. The thermal conductivity of a single disk measured by this method should be consistent to $\pm 5 \%$ with Ratcliffe's absolute values. This figure is usually less than the variation from disk to disk for most rocks. An axial pressure of 100 bars was applied across the divided bar to ensure good surface-to-surface contact of the sample with the divided bar. Mean sample temperatures were kept within $\pm 5^{\circ} \mathrm{C}$ of their in situ temperatures, and all samples were saturated with degassed water prior to measurement. For disks whose diameters did not vary by more than $\pm 5 \%$ from the standard diameters, the true conductivity was calculated from the measured conductivity by using the multiplicative factor [Jaeger and Beck, 1955]

$$
\frac{l_{s}}{l_{s t}} \frac{d_{s t}^{2}}{d_{s}^{2}}
$$

where $l_{s}$ and $d_{s}$ are the thickness and diameter of the sample, respectively, and $l_{s t}$ and $d_{s t}$ are the thickness and diameter of the standard, respectively. Conductivity values have not been tabulated but are plotted in Figures 3 and 4 .

\section{Method of Data Reduction}

The heat flow $Q$ has been calculated from the relation

$$
Q=\langle K\rangle(\Delta T / \Delta z)
$$

where $\langle K\rangle$ is the mean harmonic conductivity and $\Delta T / \Delta z$ is the best-fit gradient in the undisturbed portion of the drill hole. The mean harmonic conductivity was determined from the reciprocal of the mean resistivity $\langle R\rangle$

$$
\langle R\rangle=\frac{1}{n} \sum_{i=1}^{n} R_{i}
$$

where $R_{i}$ is the measured resistivity of the $i$ th sample of a total of $n$ samples measured from a given hole. The mean gradient was determined by using the least-squares technique to fit a straight line to the temperature-depth points. Hereafter this will be referred to as the best-fit gradient for a given hole. In addition to best-fit gradients, interval gradients, normally based on 10-meter intervals, are shown for all holes in Figures 3 and 4 . These gradients represent the differences in measured temperatures divided by the depth interval between the two measuring points. Hereafter these will be referred to as the interval gradients.

Interval methods of heat-flow computation [see Roy, 1963] were not used, since, in general, conductivity-gradient correlations did not exist; all holes were drilled in crystalline rock that, except for occasional dikes and fracture zones, was homogeneous on a scale greater than two meters.

The heat flows were calculated both from the temperature-depth points corrected for steadystate topography $Q^{*}$ and from the uncorrected data $Q$ (see Table 2). The steady-state topographic correction follows the theory given by Birch [1950]. Slight modification of the final equation [Birch, 1950, equation 24] was necessary for application of the theory to drill holes [see Henyey, 1968]. Corrections were carried out to a radius of $30 \mathrm{~km}$ from each hole. An atmospheric lapse rate of $4.5^{\circ} \mathrm{C} / \mathrm{km}$ was used. Whenever the 
TABLE 1. Temperature-Depth Data for Drill Holes Studied

\begin{tabular}{|c|c|c|c|c|c|c|c|c|c|c|c|c|c|c|c|}
\hline \multicolumn{2}{|c|}{$A N-1$} & \multirow{2}{*}{$\begin{array}{l}290 \\
300\end{array}$} & \multirow{2}{*}{$\begin{array}{ll}23 & 01 \\
23.20\end{array}$} & \multirow{2}{*}{$\begin{array}{l}230 \\
240\end{array}$} & \multirow{2}{*}{$\begin{array}{l}19.50 \\
19.72\end{array}$} & \multirow{2}{*}{$\begin{array}{l}200 \\
220\end{array}$} & \multirow{2}{*}{$\begin{array}{l}15.47 \\
15.98\end{array}$} & \multirow{2}{*}{$\begin{array}{l}220 \\
230\end{array}$} & \multirow{2}{*}{$\begin{array}{c}-1 \\
1599\end{array}$} & \multirow{2}{*}{$\begin{array}{l}590 \\
600\end{array}$} & 36.87 & 200 & 20.71 & 360 & 2168 \\
\hline[)$(n])$ & $\mathrm{T}\left({ }^{\circ} \mathrm{C}\right)$ & & & & & & & & & & 37.17 & 205 & 20.83 & 370 & 2186 \\
\hline 50 & $18 \quad 39$ & & & 250 & 19.95 & 240 & 16.49 & 240 & 1621 & 610 & 37.47 & 210 & 2096 & 360 & 2203 \\
\hline 60 & 1861 & $A N$ & & 260 & 20.17 & 260 & 16.99 & 250 & 1643 & 620 & 37.76 & 215 & 21.09 & 390 & 22.30 \\
\hline 70 & 18.84 & $\underline{\mathrm{D}(\mathrm{m})}$ & $\mathrm{T}\left({ }^{\circ} \mathrm{C}\right)$ & 270 & 20.40 & 280 & 17.55 & 260 & 1664 & 630 & 38.04 & 220 & 2120 & & \\
\hline so & 1908 & 30 & 1548 & 280 & 20.62 & 300 & 18.09 & 270 & 1687 & 640 & 38.34 & 225 & 21.32 & 16. DH- & $:-70$ \\
\hline 90 & 19.33 & 40 & 1550 & 290 & 20.85 & $32 n$ & 18.66 & 280 & 17.09 & 650 & 38.64 & 230 & 21.44 & $\underline{D(n)}$ & $\underline{T}\left({ }^{\circ} \mathrm{C}\right)$ \\
\hline 100 & 1960 & 50 & 15.59 & 300 & 21.09 & 340 & 19.20 & 290 & 17.30 & 660 & $38 \quad 94$ & & & 100 & 11.92 \\
\hline 110 & 19.86 & 60 & 15.74 & 310 & 21.32 & 360 & 19.77 & 300 & 17.49 & 670 & 39.23 & 14. $\mathrm{DH}$ & $1-65$ & 110 & 1210 \\
\hline 120 & 20.12 & 70 & 1595 & 320 & 2156 & 380 & 20.30 & 310 & 1769 & 680 & 39.51 & $\underline{D(m)}$ & $\underline{T}\left({ }^{\circ} \mathrm{C}\right)$ & 120 & 12.33 \\
\hline 130 & 20.39 & 80 & 16.18 & 330 & 2179 & 400 & 20.793 & 320 & 1793 & 690 & 39.80 & 170 & 19.66 & 130 & 12.54 \\
\hline 140 & 20.64 & 90 & 16.43 & 340 & 22.03 & 402 & 20.838 & 330 & $18 \quad 14$ & 700 & 40.10 & 180 & 19.84 & 140 & 12.78 \\
\hline 150 & 20.88 & 100 & 16.68 & 350 & 22.28 & 404 & 20.895 & 340 & $18 \quad 37$ & & & 190 & 20.13 & 150 & 12.98 \\
\hline 160 & 21.14 & 110 & 16.94 & 360 & 22.52 & 406 & 20.950 & 350 & 18.59 & 11. DII- & -14 & 200 & 20.44 & 160 & 13.18 \\
\hline 170 & 21.40 & 120 & 17,19 & & & 408 & 21.007 & 360 & 18.82 & $\underline{D}(m)$ & $\mathrm{T}\left({ }^{\circ} \mathrm{C}\right)$ & 210 & 20.54 & 170 & 13.39 \\
\hline 180 & 21.65 & 130 & 17.44 & 6. LIH & & 410 & 21.060 & 370 & 19.06 & 70 & 15.80 & 220 & 20.64 & 180 & 13.60 \\
\hline 190 & 21,90 & 140 & 17.68 & $\underline{\mathrm{D}(\mathrm{m})}$ & $T\left({ }^{\circ} \mathrm{C}\right)$ & 412 & 21.119 & 380 & 19.26 & go & 16.12 & 230 & 20.83 & 190 & 13.74 \\
\hline 200 & 22.16 & 150 & 17.92 & 30 & 16.24 & 414 & 21.189 & 390 & 19.48 & 90 & 16.41 & 240 & 20.92 & 200 & 14.00 \\
\hline 210 & 22.41 & 160 & 1816 & 40 & 16.77 & 416 & 21.259 & 400 & 19.70 & 100 & 16.73 & 250 & 21.05 & 210 & 14.23 \\
\hline 220 & 22.66 & 170 & 18.40 & 50 & 17.23 & 418 & 21.327 & 410 & 19.92 & 110 & 17.05 & 260 & 21.22 & 220 & 14.45 \\
\hline 230 & 2293 & 180 & 18.64 & 60 & 17.68 & 420 & 21.378 & 420 & 20.13 & 120 & 17.37 & 270 & 21.38 & 230 & 14.67 \\
\hline 240 & 23.17 & 190 & 18.87 & 70 & 18.10 & 422 & 21.427 & 430 & 20.36 & 130 & 1767 & 280 & 21.55 & 240 & 14.88 \\
\hline 250 & 23,43 & 200 & 19.10 & 80 & 18.51 & 424 & 21.497 & 440 & 20.60 & 140 & 17.96 & 290 & 21.71 & 250 & 15.09 \\
\hline 260 & 23.71 & 210 & 19.34 & 90 & 18.90 & 426 & 21.608 & 450 & 20.84 & 150 & 18,25 & 300 & 21.91 & 260 & 15.31 \\
\hline 270 & 23.97 & & & 100 & 19.28 & 428 & 21.665 & 460 & 21.07 & 160 & 18.51 & 310 & 22.08 & 270 & 15.52 \\
\hline 280 & 24.20 & 4. $\mathrm{L}, \mathrm{H}$ & & 110 & 19.64 & 430 & 21.717 & 470 & 21.34 & 170 & 18.78 & 320 & 22.24 & 280 & 15.73 \\
\hline 290 & 24.45 & $\underline{D(m)}$ & $\underline{T}\left({ }^{\circ} \mathrm{C}\right)$ & 120 & 19.98 & 432 & 21.754 & 480 & 21.59 & 180 & 19.04 & 330 & 22.42 & 290 & 15.94 \\
\hline 300 & 24.70 & 30 & 19.79 & 130 & 20.34 & 434 & 21791 & 490 & 21.90 & 190 & 19.30 & 340 & 22.57 & 300 & 16.15 \\
\hline 310 & 24.95 & 40 & 19.94 & 140 & 20.69 & 436 & 21.855 & 500 & 22.25 & 200 & 19.56 & 350 & 22.74 & 310 & 16.36 \\
\hline 320 & 25.18 & 50 & 20.08 & 150 & 21.02 & 438 & 21.907 & 510 & 22.54 & 205 & 19.69 & 360 & 22.94 & 320 & 16.57 \\
\hline 330 & 25.40 & 60 & 20.23 & 160 & 21.35 & 440 & 21.950 & & & 210 & 19,82 & 370 & 23.10 & 325 & 16.67 \\
\hline 340 & 25.66 & 70 & 20.42 & 170 & 21.65 & 442 & 21.993 & 10. LV & & 215 & 19.96 & 380 & 23.27 & & \\
\hline 350 & 25.88 & 80 & 20.62 & 180 & 21.96 & 444 & 22050 & $\underline{\mathrm{D}(\mathrm{m})}$ & $\underline{\mathrm{T}\left({ }^{\circ} \mathrm{C}\right)}$ & 220 & 20.09 & 390 & 23.47 & 17. $110-$ & -1 \\
\hline 360 & 26.12 & 90 & 20.84 & 190 & 22.31 & $4+6$ & 22.098 & 200 & 25.46 & & & 400 & 23.67 & $\underline{D(m)}$ & $\mathrm{T}\left({ }^{\circ} \mathrm{C}\right)$ \\
\hline & & 100 & 21.08 & 200 & 22.65 & 448 & 22.047 & 220 & 26.00 & 12. $\mathrm{DH}-$ & $-15 A$ & 410 & 23.90 & 20 & 14.65 \\
\hline 2. $\mathrm{AV}$ & & 110 & 21.33 & 210 & 22.99 & 450 & 22.193 & 240 & 26.55 & $\underline{\mathrm{D}(13)}$ & $\mathrm{T}\left({ }^{\circ} \mathrm{C}\right)$ & 420 & 24.09 & 40 & 1671 \\
\hline$\underline{D(m)}$ & $\mathrm{T}\left({ }^{\circ} \mathrm{C}\right)$ & 120 & 21.56 & 220 & 23.32 & 452 & 22.243 & 260 & 27.12 & 90 & 16.60 & 430 & 24.39 & 60 & 18.82 \\
\hline 40 & 17.79 & 130 & 21.84 & 230 & 23.64 & 454 & 22.292 & 280 & 27.68 & 100 & 16.76 & & & BO & 19.60 \\
\hline 50 & 17.91 & 140 & 22.11 & 240 & 23.95 & 456 & 22.339 & 300 & 28.26 & 110 & 16.92 & 15. $\mathrm{DH}$ & -67 & 100 & 20.51 \\
\hline 60 & 18.04 & 150 & 22.37 & 250 & 24.22 & 458 & 22.393 & 320 & 28.78 & 120 & 17.11 & $\underline{D}(\mathrm{~m})$ & $\mathrm{T}\left({ }^{\circ} \mathrm{C}\right)$ & 120 & 21.19 \\
\hline 70 & 18.20 & 160 & 2266 & 260 & 2450 & 460 & 22.447 & 340 & 29.33 & 130 & 17.27 & 140 & 18.26 & 140 & 21.89 \\
\hline 80 & 18.37 & 170 & 22.95 & 270 & 24.75 & 462 & 22.495 & 360 & 29.87 & 140 & 17.44 & 150 & 18.37 & 160 & 22.54 \\
\hline 90 & 18.56 & 180 & 23.22 & 280 & 2485 & & & 380 & 30.50 & 150 & 17.61 & 160 & 1847 & 180 & 23.15 \\
\hline 200 & 18.75 & 190 & 23.50 & 290 & 2506 & 8. SB- & & 400 & 31.15 & 160 & 17.79 & 170 & 18.56 & 200 & 23.63 \\
\hline 110 & 18.97 & 200 & 23.77 & 300 & 25.28 & $\underline{D(m)}$ & $\mathrm{T}\left({ }^{\circ} \mathrm{C}\right)$ & 410 & 31.47 & 170 & 1797 & 180 & 18.67 & 210 & 23.86 \\
\hline 120 & 19.19 & 210 & 24.05 & 310 & 23.54 & 120 & 1213 & 420 & 31.76 & 180 & 18.15 & 190 & 18.82 & 220 & 24.17 \\
\hline 130 & 19.41 & & & 320 & 25.79 & 140 & 12.46 & 430 & 32.07 & 190 & 18.34 & 200 & 18.95 & 230 & 24.23 \\
\hline 140 & 19.63 & 5. $\mathrm{I}-\mathrm{H}$ & & 330 & 26.08 & 160 & 12.83 & 440 & 32.37 & 200 & 18.52 & 210 & 19.05 & 240 & 24.48 \\
\hline 150 & 19.88 & $\underline{D}(\mathrm{~m})$ & $\mathrm{I}\left({ }^{\circ} \mathrm{C}\right)$ & 335 & 26.20 & 180 & 13.20 & 450 & 32.68 & 210 & 18.71 & 220 & 19.17 & 250 & 24.63 \\
\hline 160 & 20.13 & 100 & 16.78 & 340 & 26.44 & 200 & 13.56 & 460 & 32.98 & 220 & 18.89 & 230 & 19.29 & 260 & 24.778 \\
\hline 170 & 20.37 & 110 & 16.96 & 345 & 27.15 & 210 & 13.71 & 470 & 33.30 & & & 240 & 1942 & 265 & 24.856 \\
\hline 180 & 20.59 & 120 & 17.16 & 350 & 27.47 & 220 & 13.88 & 480 & 33.63 & 13. $\mathrm{DH}-$ & -43 & 250 & 19.56 & 270 & 24.908 \\
\hline 190 & 20.82 & 130 & 1735 & 355 & 27.71 & 230 & 1410 & 490 & 33.93 & $\underline{\mathrm{D}(\mathrm{m})}$ & $\mathrm{T}\left({ }^{\circ} \mathrm{C}\right)$ & 260 & 19.76 & 275 & 25013 \\
\hline 200 & 21.05 & 140 & 1756 & 360 & 27.91 & 240 & 14.27 & 500 & 34.24 & 130 & 19.15 & 270 & 19.94 & 280 & 25,149 \\
\hline 210 & 21.28 & 150 & 17.76 & & & 250 & 14.42 & 510 & 34.56 & 140 & 19.38 & 280 & 20.11 & 285 & 25.300 \\
\hline 220 & 21.52 & 160 & 17.97 & 7. $\mathrm{SB}-$ & & 260 & 14.61 & 520 & 3486 & 150 & 1959 & 290 & 20.28 & 290 & 25.453 \\
\hline 230 & 21.74 & 170 & 1819 & $\underline{D(m)}$ & $T\left({ }^{\circ} \mathrm{C}\right)$ & 270 & 14.78 & 530 & 35,16 & 160 & 19.80 & 300 & 20.47 & 295 & 25607 \\
\hline 240 & 21.96 & 180 & 18.40 & 100 & 13.23 & & & 540 & 3542 & 170 & 20.03 & 310 & 20.74 & 300 & $25.75 ;$ \\
\hline 250 & 22.18 & 190 & 1862 & 120 & 13.67 & 9. $\mathrm{SB}-$ & -10 & 550 & 35.68 & 180 & 20.25 & 320 & 20.99 & & \\
\hline 260 & 22.39 & 200 & $18 \quad 84$ & 140 & 14.11 & $\underline{D(m)}$ & $\underline{\mathrm{T}\left({ }^{\circ} \mathrm{C}\right)}$ & 560 & 35.95 & 185 & 20.36 & 130 & 21.15 & & \\
\hline 270 & 22.60 & 210 & 19.06 & 160 & 14.56 & 200 & 15.36 & 570 & 36.23 & 190 & 20.46 & 340 & 21.33 & & \\
\hline 280 & 22.85 & 220 & 19.28 & 180 & - - & 210 & 15.57 & 580 & 36.52 & 195 & 20.59 & 350 & 21.53 & & \\
\hline
\end{tabular}


terrain correction exceeds about $10 \%$, the limits of this first-order theory have probably been approached or exceeded [Roy et al., 1968]. In rugged terrain, unusual surface temperature distributions often prevail, and a simple linear decrease of temperature with altitude is not sufficient to determine the topographic effect. A couple of instances will be noted later in which the limit of the theory has probably been reached.

Time-dependent terrain corrections involving probable rates of uplift and erosion have been considered earlier [Henyey, 1968]. However, for reasonable choices of these parameters, it was found that their effects on the corrected heat flow are insignificant, and for that reason they have not been included here.

\section{Data}

The seventeen heat-flow determinations will be discussed in terms of the five regions in which
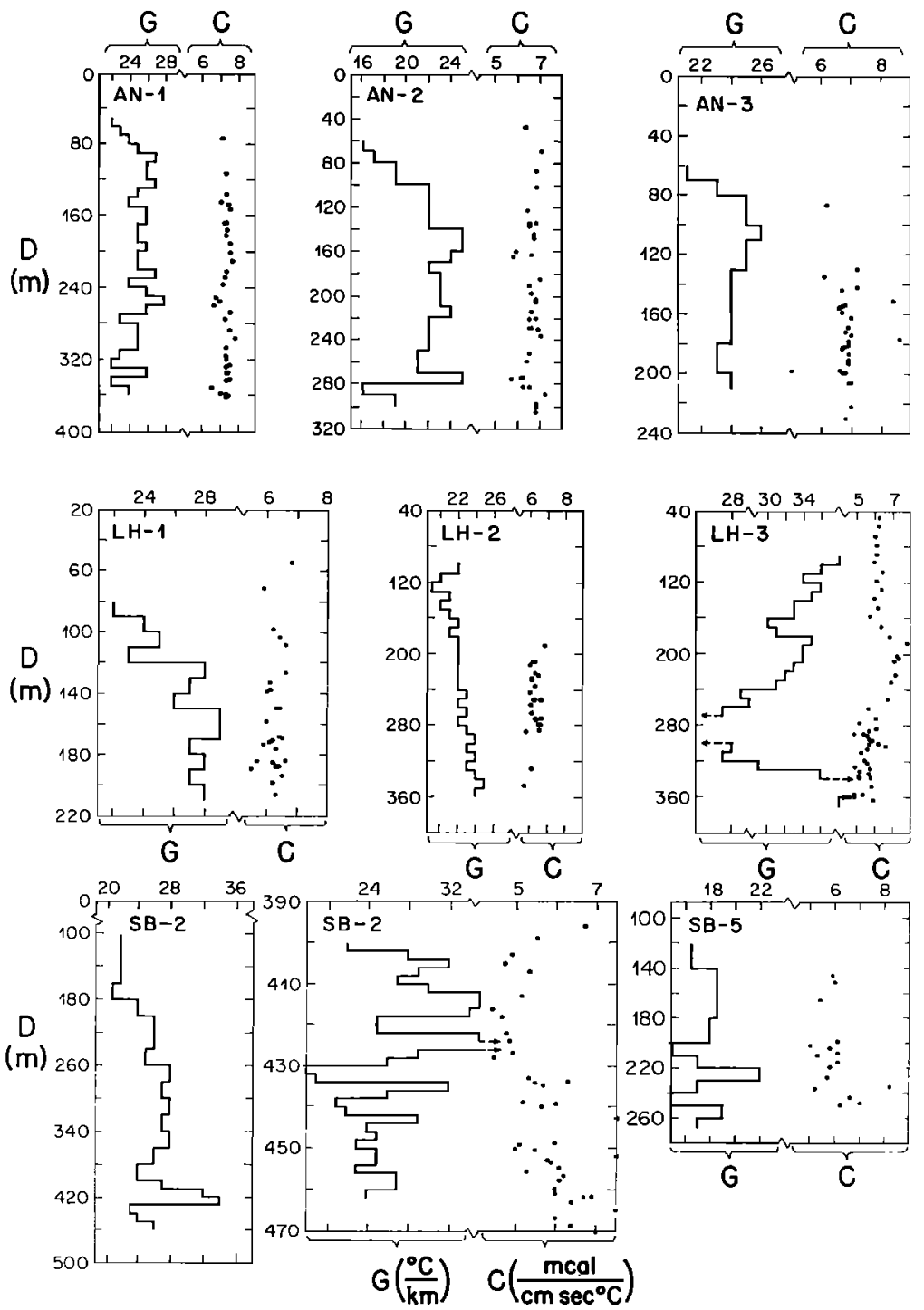

Fig. 3. Ten-meter interval gradients and thermal conductivities for drill holes used for heatflow measurement. (Arrows indicate where gradients are too large or too small to be shown on the chosen scale. These deviations are discussed in the text.) 

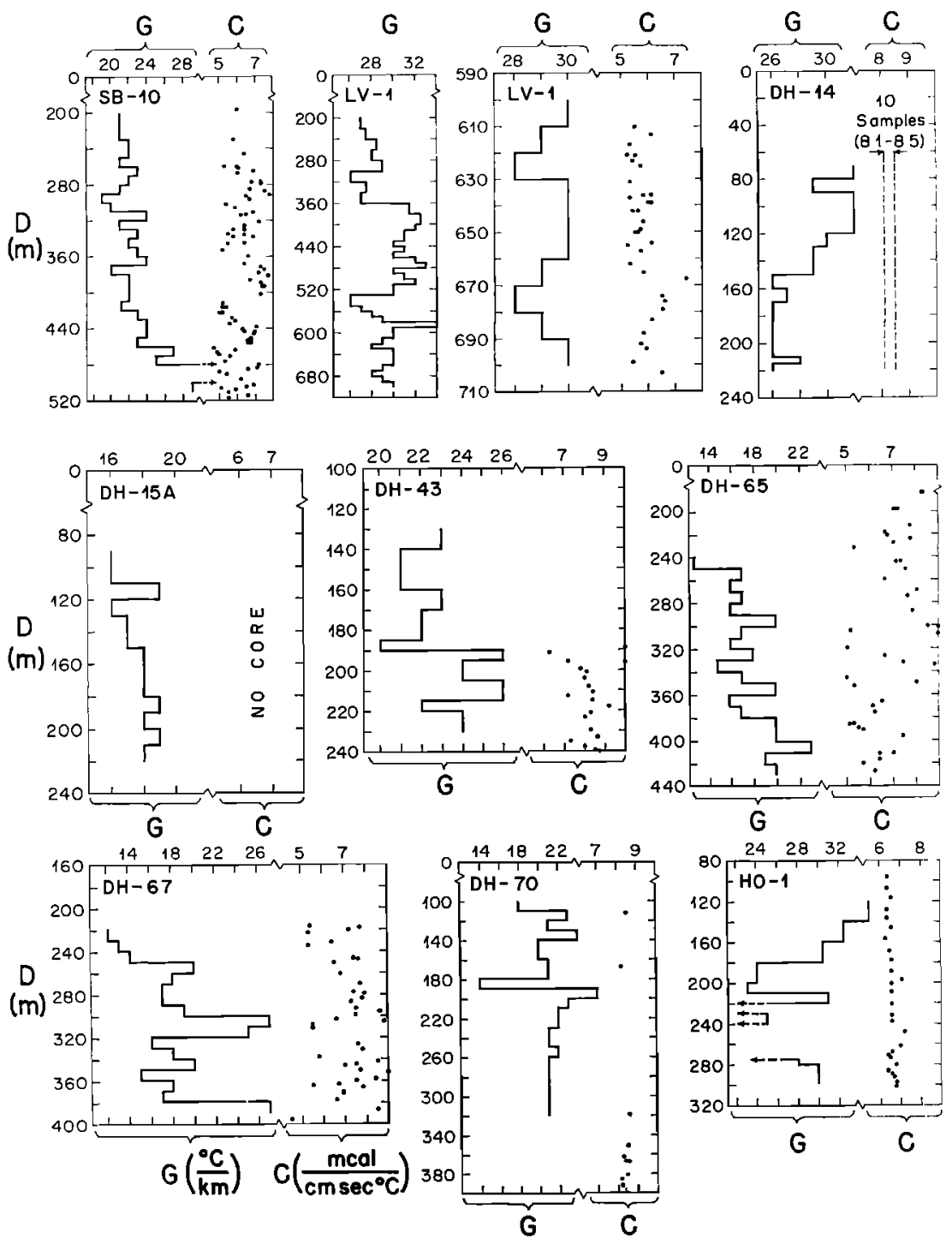

Fig. 4. Ten-meter interval gradients and thermal conductivities for drill holes used for heat-flow measurement.

they occur (see Figure 1): Anza, San Bernardino Mountains-Lucerne Valley, Lake Hughes, Tehachapi Mountains, and Hollister. A summary of the data is presented in Table 2, giving locations, gradients, resistivities, and heat flows for each hole. The table also indicates the depth range for each hole used to calculate the heat flow. Standard errors are also given in Table 2 and will be implied in following references to errors in the text. In addition to interval gradients, Figures
3 and 4 also show thermal conductivities for each hole.

\section{Heat Flow near Anza, California}

AN-1, AN-2, and AN-3 were drilled along the San Jacinto fault near the town of Anza. These holes are located in a hornblende-biotite tonalite, a part of the pre-Upper Cretaceous crystalline complex of the Peninsular Range province of southern California [Sharp, 1967]. The region 
in the vicinity of the San Jacinto fault is one of the most seismically active areas in California. Field relationships suggest up to $36 \mathrm{~km}$ of rightlateral slip and $13 \mathrm{~km}$ of vertical movement on the San Jacinto alone, corresponding to a rate of movement of at least $0.3 \mathrm{~cm} /$ year since Pleistocene time [Sharp, 1967]. In addition, triangulation surveys have established current rates of strain of at least $3 \mathrm{~cm} /$ year across the San Jacinto and related faults to the south of Anza [Whitten, 1955].

$A N-1, A N-2$, and AN-3 were drilled 4, 13, and $1 \mathrm{~km}$, respectively, west of the San Jacinto fault. Figure 2 shows the hole locations and distribution of major rock types. As may be seen, crystalline rocks occur on both sides of the fault; it is inferred that this means a symmetry in the thermal characteristics, so that lateral heat transport should not play a dominant role. The region is covered with numerous minor faults, and several hot springs occur in the area. No holes were drilled near hot springs, since it is not possible to evaluate the effects of heat transport due to such mechanisms. We have assumed that when the temperature and conductivity versus depth curves are well behaved, the heat flows determined are correct and are not the result of perturbing effects. Because of the homogeneity of the tonalite, the conductivities fall within a rather narrow range of about $\pm 10 \%$ about the mean.

The interval gradients for AN-1 on a 10meter scale (Figure 3) are almost all within $\pm 10 \%$ of the best-fit gradient throughout the temperature-depth profile. Similarly, the conductivities are well behaved, all within $\pm 3 \%$ of the mean value. We conclude that these results allow a precise determination of $Q=1.84 \pm$ $0.02 \mathrm{HFU}$, and $Q^{*}=1.87 \pm 0.02 \mathrm{HFU}$ at this locality ( $1 \mathrm{HFU}=1 \mu \mathrm{cal} / \mathrm{cm}^{2} / \mathrm{sec}$; hereafter the heat-flow units will be dropped).

The data for AN-2 show a distinct curvature in the temperature-depth profile, and the gradients on a 10 -meter interval range from $16^{\circ}$ to $25^{\circ} \mathrm{C} / \mathrm{km}$. The conductivity appears to reflect the sudden changes in the gradient at $\sim 280$ meters,

TABLE 2. Pertinent Location and Heat-Flow Data for Drill Holes Studied

\begin{tabular}{|c|c|c|c|c|c|c|c|c|c|c|c|c|c|c|}
\hline Fole & Quadrangle & N. Iat. & W. Longy. & C.Г. & D.R. & G & S.E.G. & $Q$ & $Q^{\prime}$ & S.E.Q. & $\overline{\mathrm{R}}$ & S.E. $\overline{\mathrm{R}}$ & $\mathrm{N}$ & $d$ \\
\hline$A N-1$ & $\begin{array}{l}\text { Bucksnort } \\
\text { Mtn. (? " l) }\end{array}$ & $33^{\circ} 29.5^{\prime}$ & $116^{\circ} 35 \quad 81$ & 3900 & $160-360$ & 25.04 & $\pm 0,10$ & 1.84 & 1.87 & \pm 0.02 & 135.8 & \pm 1.1 & 29 & $4 \mathrm{~km}$ \\
\hline$A N-2$ & Hemet (15") & $33^{\circ} 31.6^{\prime}$ & $116^{\circ} 48.4^{\prime}$ & $3+20$ & $110-300$ & 22.63 & \pm 0.12 & 1.49 & 1.46 & \pm 0.02 & J 51,7 & \pm 1.6 & 32 & $13 \mathrm{~km}$ \\
\hline$A N-3$ & Idyliwild $\left(15^{\prime \prime}\right)$ & $33^{\circ} 32.3^{1}$ & $116^{\circ} 36.21$ & 4800 & $110-210$ & 23.94 & \pm 0.09 & 1.63 & 1.76 & \pm 0.03 & 145.6 & \pm 2.4 & 31 & $1 \mathrm{~km}$ \\
\hline $\mathrm{I}, \mathrm{H}-1$ & $\begin{array}{l}\text { Lake Hughes } \\
(7 \mathrm{ll})\end{array}$ & $34^{\circ} 44.1^{\prime}$ & $1182 ; .71$ & 2500 & $120-210$ & 27.70 & \pm 0.09 & 1.72 & 1.72 & \pm 0.02 & 161.0 & $\pm 1,3$ & 30 & $B \mathrm{~km}$ \\
\hline I.I I-2 & $\begin{array}{l}\text { Lake Hughes } \\
\text { (7 il) }\end{array}$ & $34^{\circ} 41.2^{\prime}$ & 118.2611 & $377 i$ & $180-280$ & 22.21 & \pm 0.04 & 1.39 & 1.56 & \pm 0.02 & 160.0 & $\pm 1,5$ & 25 & $1 \mathrm{~km}$ \\
\hline I. II- 3 & $\begin{array}{l}\text { Lake Hughes } \\
\text { (7 1') }\end{array}$ & $34^{\circ} 39.1^{\prime}$ & 1182921 & $2 m 0$ & $150-250$ & 32.80 & \pm 0.14 & 1.92 & 1.68 & \pm 0.03 & 1710 & \pm 27 & 52 & $4 \mathrm{~km}$ \\
\hline$S B-2$ & $\begin{array}{l}\text { San Bernardino } \\
\text { North }(7\end{array}$ & $34^{\circ} 15.0^{\prime}$ & $117^{\circ} 1921$ & 1600 & $430-462$ & 24.56 & \pm 0.14 & 1.50 & 1.63 & \pm 0.04 & 1643 & \pm 4.0 & 26 & $5 \mathrm{~km}$ \\
\hline $5 \sqrt{3}-5$ & $\begin{array}{l}\text { Cedar Springs } \\
(7 \text { 11) }\end{array}$ & $34^{\circ} 16.3^{\prime}$ & $117^{\circ} 19.7$ & $41(6)$ & $200-270$ & 17.66 & \pm 0.26 & 1.05 & 1.08 & \pm 0.04 & 1682 & \pm 4.8 & 16 & $7 \mathrm{~km}$ \\
\hline $5 \pi-10$ & $\begin{array}{l}\text { Cedar Sprungs } \\
\left.(7)^{\prime \prime}\right)\end{array}$ & $34^{\circ} 15.1^{4}$ & 1170.79 & 4700 & $300-440$ & 22.19 & \pm 0.06 & 1.39 & $1=8$ & \pm 0.03 & $1(00) .0$ & \pm 2.5 & 67 & $5 \mathrm{~km}$ \\
\hline$n I I-14$ & $\begin{array}{l}\text { La Liebre } \\
\text { Ranch (7 })\end{array}$ & $34^{\circ} 51.7^{\prime}$ & $11 x^{\prime} 44 \quad 51$ & $, 111,5$ & $150-220$ & 26.23 & \pm 0.05 & 2.19 & 2.03 & \pm 0.02 & 12100 & \pm 08 & 10 & $3 \mathrm{~km}$ \\
\hline JU1-15A & $\begin{array}{l}\text { La Liebre } \\
\text { Ranch (7 ") }\end{array}$ & $34^{\circ} 51.3^{\top}$ & $118^{\circ}+4.0^{\prime}$ & S111 & $150-220$ & 1833 & \pm 0.06 & 1.54 & 118 & \pm 0.03 & -- & $\cdots$ & $\cdots$ & $4 \mathrm{~km}$ \\
\hline I]I $=43$ & $\begin{array}{l}\text { Pastoria Creek } \\
(7 \mathrm{ll})\end{array}$ & $34^{\circ} 53.4^{\prime}$ & $118^{\circ} 46.3^{\prime}$ & 36,21 & $176-230$ & 23.80 & \pm 0.18 & 1.97 & 2112 & \pm 0.07 & 120,8 & \pm 40 & 22 & $1 \mathrm{~km}$ \\
\hline 1$) ! 1-65$ & $\begin{array}{l}\text { Pastoria Creek } \\
(7 \mathrm{ll})\end{array}$ & $34^{\circ} 56.11$ & $118^{\circ} 48 \quad 81$ & 2594 & $320-420$ & 17.99 & \pm 0.28 & 1.27 & 1.29 & \pm 0.04 & 145.5 & \pm 3.9 & 51 & $8 \mathrm{~km}$ \\
\hline I) $11-67$ & $\begin{array}{l}\text { Pastoria Creek } \\
(7 \text { I) }\end{array}$ & $34^{\circ} 55.9^{\prime}$ & $118^{\circ} 48.5^{\prime}$ & 2924 & $320-390$ & 18.23 & 0.47 & 1.26 & 1.33 & \pm 0.05 & 194.7 & \pm 3.9 & 40 & $7 \mathrm{~km}$ \\
\hline DII -70 & Lebec $(717)$ & $34^{\circ} 52.3^{\prime}$ & $118^{\circ} 45.1^{\prime}$ & $4 \times 32$ & $210-320$ & 21.22 & \pm 0.04 & 1.78 & 2.21 & \pm 0.02 & 1189 & \pm 0.6 & 14 & $2 \mathrm{~km}$ \\
\hline $110-1$ & Gonzales (15') & $36^{\circ} 43.3^{\prime}$ & $121^{\circ} 24.4^{\prime}$ & 1080 & $278-300$ & 30.22 & \pm 0.06 & 1.99 & 1.71 & \pm 0.01 & 152.0 & \pm 0.9 & 24 & $3 \mathrm{~km}$ \\
\hline$L V-1$ & $\begin{array}{l}\text { Rodman Mts - } \\
\text { (15') }\end{array}$ & $34^{\circ} 370^{\prime}$ & $116^{\circ} 434^{1}$ & 3685 & $600-700$ & 29.27 & \pm 0.07 & 1.69 & 1.65 & $\pm 0 \quad 03$ & 173.5 & \pm 26 & 30 & $50 \mathrm{~km}$ \\
\hline
\end{tabular}

C.E., collar elevation; D.R., depth range used in heat-flow determination; $G$, uncorrected best-fit gradient; S.E.G., standard error of gradient; $Q$, uncorrected heat flow; $Q^{*}$, heat flow corrected for steadystate topography; S.E.Q*, standard error of heat flow; $R$, mean resistivity; S.E.R., standard error of resistivity; $N$, number of conductivity determinations; $d$, distance of drill hole from nearest major strike-slip fault. 


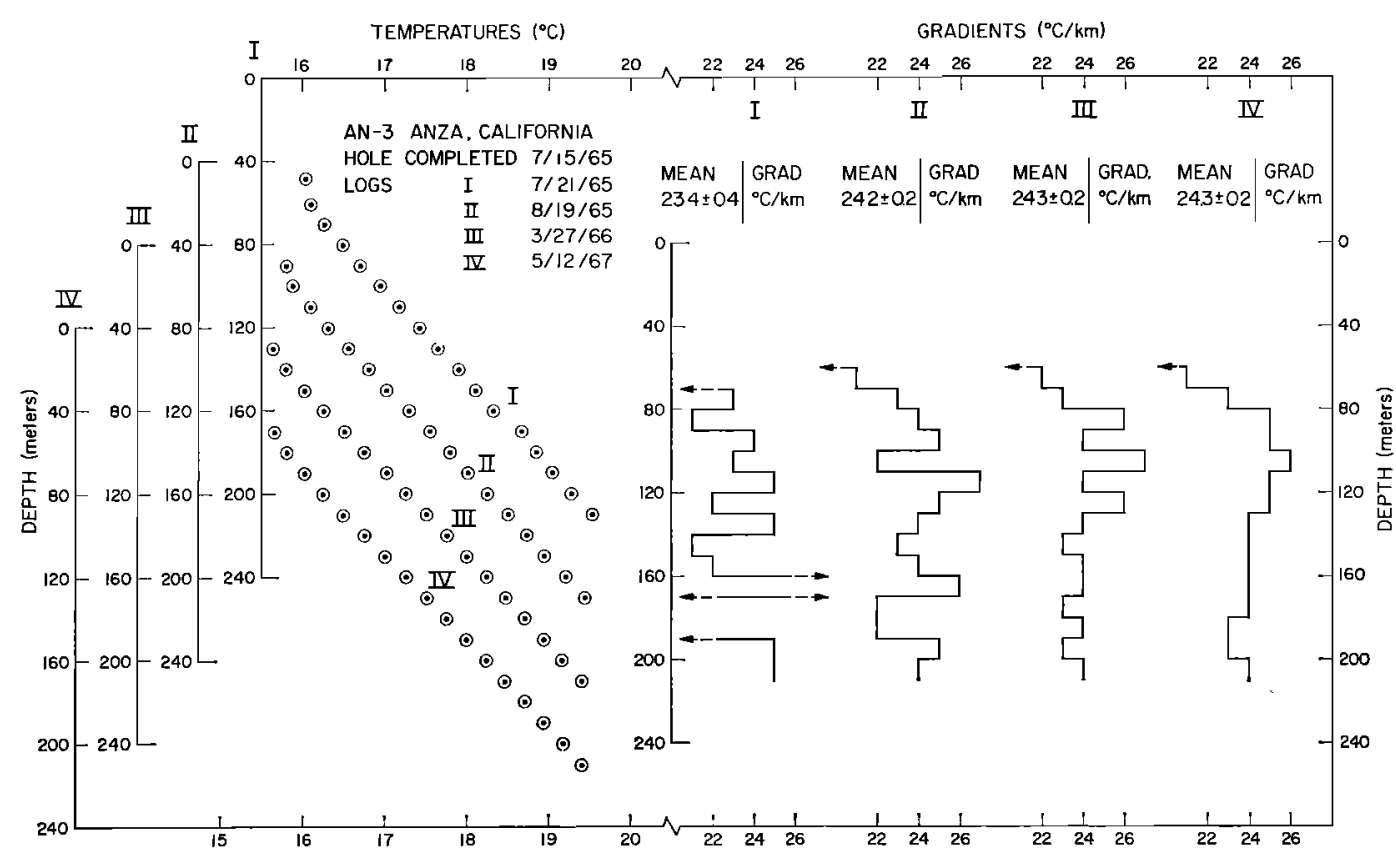

Fig. 5. Temperature equilibration study for drill hole AN-3. Temperature-depth plots for the four loggings are vertically staggered to prevent data-point overlap.

but the quantity $k_{z} \nabla_{z} T$ does not appear to be precisely conserved. The measurements at depths shallower than 100 meters seem to reflect changes in the mean annual surface temperature or other surface effects. We have rejected these results in calculating the best-fit gradient. The gradient obtained from this hole is considered reliable although the rapid changes at $\sim 280$ meters are not entirely explained.

The data from AN-3 show a uniform gradient, except for the first 70 meters. The curvature in the first 70 meters is probably due to lateral heat transport resulting from defoliation near the hole. The conductivities are found to be uniform, with exceptions attributed to weathering. The heat flow determined here is also considered reliable, although the presence of significant topographic relief causes a relatively large correction to the heat flow as compared with the other two Anza holes. The result from $\mathrm{AN}-3$ is particularly impressive, since the hole was drilled almost on the San Jacinto fault, and the rocks were only moderately fractured and weathered. Localities somewhat farther to the north and with less local relief show profound weathering profiles and were not chosen for this reason.
A study of the temperature profile as a function of the time after drilling was made for all holes that we drilled. The results for AN-3, which are typical, are shown in Figure 5. This hole was monitored one week, one month, eight months, and two years after drilling. The important results are (1) the best-fit gradient remained the same to within $5 \%$ for all four temperature profiles, and (2) the variability of the 10-meter interval gradients decreases with increasing time. The constancy of the best-fit gradient confirms the results of Jaeger [1961] and suggests that reliable heat-flow values can be determined in appropriate cases almost immediately after drilling.

The corrected heat-flow values at $A N-1$ and AN-3, which are about $3 \mathrm{~km}$ apart (see Figure 2 ), are 1.9 and 1.8 , respectively, whereas the heat flow at $A N-2$, approximately $10 \mathrm{~km}$ to the west, is somewhat lower (1.5). These results in an area that is typical of the southern California batholith can be contrasted with the much lower values of $\sim 1.0$ found in the Sierra Nevada in very similar rock types [Lachenbruch, 1968; Roy et al., 1968]. The heat-flow values near Anza are more like those found in the Basin 
and Range province farther to the east. Within experimental error, the differences in heat flow seem to correlate with distance from the fault. No exact comparison can be made because of the intrinsic variability of heat-flow determinations due to a variety of causes. A more complete study could establish the reality of this correlation. Additional holes farther from the fault and on the east side of the fault would be particularly important.

\section{Heat Flow in the San Bernardino Mountains, California}

Three holes (SB-2, SB-5, and SB-10) drilled by the California State Department of Water Resources along proposed tunnel alignments in the San Bernardino Mountains at distances of 5,7 , and $5 \mathrm{~km}$ from the San Andreas fault, respectively, were cleaned and cased. A fourth hole, LV-1, about $50 \mathrm{~km}$ to the northeast near Lucerne Valley, drilled for mineral exploration by the Southern Pacific Land Company, was deepened an additional 100 meters and cased.

These holes presented an opportunity to investigate heat flow along the San Andreas fault by using locations near and distant from the fault trace, as shown in Figure 1. The southwestern-facing escarpment of the San Bernardino Mountains defines the trace of the San Andreas fault in this region. Although this section of the San Andreas fault does not currently have a high seismicity, it lies at the southeastern extent of the ground break from the 1857 Fort Tejon earthquake.

Figure 2 shows the drill holes relative to the local geology. The three holes in the San Bernardino Mountains are located in Cretaceous (?) [Bailey and Jahns, 1954] crystalline gneisses ranging from diorite to granite in composition. A cross section $A A^{\prime}$ in Figure 2 shows the steep escarpments bounding the range and the inferred presence of crystalline rocks on both sides of the fault. Again, it should be noted that there are a multitude of associated faults in this region.

The temperature-depth curve for SB-2 (see tabulated values, Table 1 ) is relatively uniform, except for breaks at about 200 and 420 meters, as can be seen in Figure 3, which shows 2-meter interval gradients for the bottom 10 meters of hole in addition to 10 -meter interval gradients. The best-fit gradient from the bottom 30 meters of hole, which was used in the determination of
$Q$ and $Q^{*}$, differs from the best-fit gradient for the entire hole by less than $10 \%$. The 10 -meter interval gradients for SB-2 are shown in Figure 3 , along with 2-meter interval gradients for the bottom 60 meters. The errors (Table 2) indicate that the best-fit gradient and mean harmonic conductivity chosen are reliable estimates. The bottom 30 meters of gradient was used for the heat-flow determination, since suitable core existed for this interval only. A large-scale discontinuity in gradient between 400 and 430 meters (Figure 3 ) is attributed to a known change in conductivity. The wide range in conductivities in the bottom 30 meters is due to the banding of minerals on a scale of several centimeters.

The 10-meter interval gradients from SB-5 (Figure 3) range from $14^{\circ} \mathrm{C} / \mathrm{km}$ to $18^{\circ} \mathrm{C} / \mathrm{km}$, and the error limits on the best-fit gradient (Table 2) suggest that this is not a reliable determination. The extremity of the neighboring topography and observations suggesting water movement in the local rock lead us to interpret the heat flow observed at this locality only as a lower bound. The value has not been plotted in Figure 8.

From Figure 4 and Table 1, it can be seen that the temperature-depth curve for SB-10 is well behaved between 200 and 460 meters. The 10-meter-interval gradients range between $20^{\circ} \mathrm{C} / \mathrm{km}$ and $24^{\circ} \mathrm{C} / \mathrm{km}$, and the error limits (Table 2) on the best-fit gradient are small. However, below 460 meters there is an obvious curvature in the temperature profile. This curvature is attributed to a faulted zone in which the rock was fractured and altered. Reliable conductivity measurements could not be obtained for this interval, and hence it was excluded from that part of the temperature profile used to determine $Q$ and $Q^{*}$.

The hole near Lucerne Valley (LV-1, Figure 2) was drilled in a hornblende diorite cut by numerous, steeply dipping, andesitic dikes in the pre-Tertiary crystalline complex of the Mojave Desert block [Dibblee, 1964]. The original core could not be located, and consequently the hole was deepened by 100 meters to obtain material for conductivity determinations. $Q$ and $Q^{*}$ were thus calculated from the mean harmonic conductivity and best-fit gradient of the bottom 100 meters. It will be noted (Figure 4) that a distinct break in gradient occurs at 360 meters, suggesting a change in conductivity at this 
depth. In order to investigate this possibility, a 15-meter surface-core sample was taken a short distance from the original hole and was found to have a higher conductivity than the rock at depth. Thus the conductivity-gradient correlation was established.

SB-2 and SB-10 (approximately $1 \mathrm{~km}$ apart) give the same $Q^{*}$ of 1.6 within the limits of error (Table 2). A $Q^{*}$ value of 1.1, which is inferred to be a lower bound, was determined for SB-5. The corrected heat flow at LV-1 is also 1.6 and is the same as a value reported by Roy et al. [1968] about $6.5 \mathrm{~km}$ to the northeast in a complex geological environment. It is believed from consideration of these measurements that the heat flow is relatively uniform northeast of the San Andreas fault in the San BernardinoLucerne Valley region, with an areal average of about 1.6. This average value is at the low end of the range of values found for the Basin and Range province [Roy et al., 1968].

\section{Heat Flow near lake Hughes, California}

LH-1, LH-2, and LH-3 were drilled in preTertiary Mesozoic (?) crystalline rocks [Dibblee, 1961] in the vicinity of the San Andreas fault near Lake Hughes, as shown in Figure 2. LH-1 and LH-2 were drilled $8 \mathrm{~km}$ and $1 \mathrm{~km}$, respectively, northeast of the San Andreas fault in decomposed quartz monzonite [Dibblee, 1961]. LH-3 was drilled $4 \mathrm{~km}$ southwest of the fault in a slightly foliated gneissic diorite. In the Lake Hughes region, as in the case of Anza, crystalline rocks are mapped on both sides of the fault.

The San Andreas fault in this area is characterized by a well-developed rift valley about $1 \mathrm{~km}$ wide. Major offsets along the fault occurred during the 1857 Fort Tejon earthquake, but since then the region has had relatively low seismicity, and no creep offsets have been recognized in the last 50 years.

LH-1 could not be drilled deeper than 220 meters without substantially increasing the cost, owing to the highly fractured and decomposed nature of the rock. However, it can be seen from the temperatures in Table 1 and the 10-meter interval gradients in Figure 3 that the temperature profile below 120 meters is regular and almost certainly undisturbed. Again, the curvature above 120 meters is attributed to surface temperature effects. Although perhaps two-thirds of the core was too badly damaged to obtain conductivity samples, the remainder retained enough physical integrity to permit an ample number and distribution of measurements. The small terrain correction and limits of error (Table 2) further support the premise that the heat flow obtained from LH-2 is reliable. It is felt from this result that holes drilled to a depth of 200 meters are suitable for heat-flow determinations in regions of subdued topography, i.e., local relief less than approximately one-half hole depth.

LH-2 was drilled to a depth of 180 meters by the California State Department of Water Resources and deepened to 360 meters by us. The physical characteristics of the core were similar to those encountered in LH-1, with a smaller percentage of usable core. Only two conductivity measurements could be made in the final 70 meters of hole. The slightly higher gradient in this interval (see Figure 3) is attributed to the extreme decomposition of the rock. For this reason only the central portion of the hole was used to determine $Q$ and $Q^{*}$, where an adequate number of conductivity measurements could be made and the gradient is well behaved. Again, as in the case of $\mathrm{AN}-3$, it is important to emphasize that a reliable heat-flow determination was made within $1 \mathrm{~km}$ of the San Andreas fault in badly altered rock. We suggest that partially decomposed rock can become self-grouted, the clays and silts effectively sealing up cracks, thus eliminating groundwater circulation. Waterpumping tests performed by the Department of Water Resources on the original hole showed that virtually no water could be injected into the formation.

From Figure 3 it can be seen that the temperature profile for LH-3 is extremely irregular. The 10-meter interval gradients range from less than $20^{\circ} \mathrm{C} / \mathrm{km}$ to more than $40^{\circ} \mathrm{C} / \mathrm{km}$ and are not correlated with a corresponding variability in conductivity. A large fracture zone was encountered between 240 and 270 meters and is apparently responsible for a significant amount of water circulation, primarily in the lower portions of the hole. It was felt, however, that a satisfactory heat-flow determination could be made using the portion of the hole between 150 and 250 meters, together with the bottom hole point where the temperatures appeared to have both long- and short-term stability. Circulating water in a drill hole should only tend to produce an isothermal condition, and hence the resulting 
heat flow would tend to be a lower bound. In addition to the uncertainty in gradient, the large topographic correction of about $12 \%$ (Table 2) adds to an over-all uncertainty in $Q^{*}$ of perhaps $\pm 10 \%$. It is likely that the limits of the first-order terrain theory used here [Birch, 1950] have been exceeded.

The confidence in the heat-flow determination of 1.7 obtained from LH-3 is increased when compared with the values of 1.7 at LH-1 and 1.6 at $\mathrm{LH}-3$. These three determinations are also similar to those from the San BernardinoLucerne Valley region, suggesting uniformity of heat flow over a large part of the southwestern margin of the Mojave block.

\section{Heat Flow in the Tehachapi Mountains, CaLifornia}

Six holes (DH-14, DH-15A, DH-43, DH-65, DH-67, and DH-70), drilled by the California State Department of Water Resources along a tunnel alignment through the Tehachapi Mountains, were used for heat-flow measurements. DH-43 was deepened an additional 60 meters, and all were cleaned and cased with perforated pipe. The holes are in a perpendicular profile across the Garlock fault, as shown in Figure 2. They are located in three major rock types: (1) a Mesozoic, gneissic hornblende diorite that crops out extensively on the north flank of the range and is terminated to the south by the Garlock fault; (2) a Mesozoic coarse-grained granite that crops out along the south flank of the range and is terminated to the north by the Garlock fault; and (3) a pre-Cambrian (?) quartzmica schist (Pelona) that forms a narrow band (1-2 km) between the two branches of the Garlock fault. Although crystalline rocks occur on both sides of the fault in this region, as shown by the Tehachapi Mountains cross section $A A^{\prime}$ in Figure 2, the thermal conductivity of the rock north of the Garlock fault is about $20 \%$ lower than that of the rock south of the fault (see Table 2), and we can reasonably expect lateral heat transfer near the fault. In the appendix we consider this refraction in terms of a simplified model.

It is generally recognized that the south branch of the Garlock fault has been the most recently active segment; however, evidence for Recent activity is lacking along the length of the fault. Smith [1960] argues that movement along a portion of the fault to the east has not occurred in the last 50,000 years. Furthermore, seismicity [Allen et al., 1965] and geodetic [Meade and Small, 1966] surveys along the Garlock show negligible strain-energy release or accumulation when compared with other fault zones in southern California.

DH-65 and DH-67 were drilled within 2/3 $\mathrm{km}$ of each other and about $8 \mathrm{~km}$ north of the Garlock fault in the gneissic diorite. The behavior of the temperature profile and the range in conductivities for DH-65 and DH-67 are similar. Figure 4 shows that the 10-meter interval gradients are moderately irregular, ranging from $14^{\circ} \mathrm{C} / \mathrm{km}$ to $26^{\circ} \mathrm{C} / \mathrm{km}$ in the bottom 200 meters of drill hole. This irregularity is also reflected by the rather large error limits on the best-fit gradients (Table 2). The conductivity values are also widely distributed, ranging from about 5 to $8.5 \mathrm{mcal} / \mathrm{cm} \mathrm{sec}{ }^{\circ} \mathrm{C}$ owing to the banding of minerals on a scale of several centimeters. The wide range in conductivity accounts in part for the variability in the gradient even on a 10-meter scale. The Tehachapi Mountains cross section $A A^{\prime}$ (Figure 2) shows that these two holes are located on the steep northern flank of the range, which accounts for a deep water table and water circulation in the upper parts of both holes, making the first 300 meters in both holes unusable. Both holes give $Q^{*}$ values of about 1.3 , but with a reasonably large uncertainty (Table 2).

DH-43 was drilled in Pelona schist between the two branches of the Garlock fault, as shown in Figure 2. A distinct break in gradient is observed to occur at about 190 meters, the point at which the additional drilling began. No conductivity measurements were made above this depth, and thus no explanation can be given for this change in the temperature profile. $Q$ and $Q^{*}$ were calculated from the temperatures below 190 meters, where the $10-$ meter interval gradient ranges from $22^{\circ}$ to $26^{\circ} \mathrm{C} / \mathrm{km}$, and the conductivities range between 7 and $9 \mathrm{mcal} / \mathrm{cm}$ sec ${ }^{\circ} \mathrm{C}$. The value of $Q^{*}=2.0$ (Table 2) is $50 \%$ higher than the values of 1.3 about $7 \mathrm{~km}$ to the north.

$\mathrm{DH}-70, \mathrm{DH}-14$, and $\mathrm{DH}-15 \mathrm{~A}$ are located in granite 2, 3.5, and $4.5 \mathrm{~km}$ south of the Garlock fault, respectively, as shown in Figure 2. Visual inspection of the core and the small range in 
conductivity measurements (8.0-8.5) from DH14 and DH-70 allowed us to conclude that the granite was uniform in composition. No systematic changes in conductivity with depth were observed, and only a small number of samples were necessary to determine the mean harmonic conductivity with high precision. Figure 4 shows that the 10-meter interval gradients for DH-14 and DH-70 are well behaved below 150 and 200 meters, respectively. The large discontinuity at about 190 meters in DH-70 is due to the effect of a single temperature anomaly at this depth. Figure 4 shows that the gradients are uniform in the intervals chosen for the calculation of $Q$ for DH-14 and DH-70. These results, coupled with the small range in conductivities, lead to reliable determinations of $Q$. However, it will be noted from Table 2 that the topographic corrections are about $-10 \%$ for $\mathrm{DH}-14$, which is in a canyon bottom, and $+20 \%$ for $\mathrm{DH}-70$, which is on the top of the neighboring ridge. DH-70 was corrected from 1.8 to 2.2 , and thus it is not clear whether the difference of 0.2 between DH-14 and DH-70 is real or an outgrowth of the large terrain correction. As noted earlier, the first-order terrain theory has probably been exceeded in the case of corrections of $10 \%$ or more.

DH-15A was drilled $4.5 \mathrm{~km}$ south of the Garlock fault and only $1 \mathrm{~km}$ south of DH-14. No core was obtained throughout the length of the hole because of the poor quality of the rock, and as a result no conductivity measurements could be made. From drill cuttings and the local geology, the lithology was inferred to be similar to that encountered in DH-14 and DH-70. For this reason, the mean resistivity of the core measured from these holes was used. The resulting heat flow is 1.5. The heat flow here seems anomalously low in comparison with the results from DH-14 and DH-70. No obvious explanation can be given for this discrepancy. The temperature-depth profile appears to be well behaved, as can be seen by comparing the mean temperature gradient with the 10-meter interval gradients in the last 70 meters. Lateral heat conduction does not appear to be responsible for this difference. In the absence of measured conductivities, it is necessary to regard the determination at DH-15A as second class, and it is futile to speculate on such disturbances as large-scale groundwater circulation below the hole or as recent movement of the water table without any evidence.

In summary, the value of 1.3 obtained from DH-65 and DH-67 is the same as a value reported by Benfield [1947] about $100 \mathrm{~km}$ to the northwest in the Great Valley. The heat flow in the interior part of the Tehachapi Mountains and south of the Garlock fault is significantly higher. This is in contrast to the low values reported for the Sierra Nevada to the north [Roy et al., 1968; Lachenbruch, 1968]. Some of this difference may be related to refraction of heat owing to juxtaposition of rock types having different conductivities and to differences in radioactivity, but in large part the change in heat flow appears to be characteristic of the Tehachapi Mountain block. The smaller-scale variability among neighboring measurements (DH-14, DH-70, DH-43) should not be considered significant at present because of lithologic complexities and the effects of topography.

\section{Heat Flow near Hollister, California}

A single hole, HO-1, was drilled $3 \mathrm{~km}$ southwest of the San Andreas fault near Hollister. The fault in this region is characterized by a few centimeters of creep offset per year [Whitten, 1955; Steinbrugge et al., 1960]. As a result of the high creep rate and the results reported in this paper, an additional eight holes have been drilled as part of a continuing program and will be reported on in a subsequent paper (R. F. Roy, J. N. Brune, and T. L. Henyey, in preparation). HO- 1 is in a quartz diorite pluton of unknown extent on the east flank of the Mesozoic Gabilan Mountains batholith, as shown in Figure 2.

The region east of the San Andreas fault is dominated by the Franciscan complex of eugeosynclinal rocks of presumably Cretaceous age. Overlying the Franciscan are thick sections of upper Cretaceous and Tertiary marine strata. The juxtaposition of these two dissimilar rock suites may cause lateral asymmetry in thermal properties to considerable depth. No conductivity measurements were made of Franciscan-type rocks, and we are unable to assess possible refraction effects.

Figure 4 shows that the 10-meter interval gradients for HO-1 are highly irregular. On the other hand, the range in conductivities is only about $10 \%$. These results, along with the fact that, with the exception of the bottom 22 meters, 
temperatures drifted as much as several hundredths of a degree during measurement, indicate that the entire hole above 280 meters is disturbed by circulating water. This disturbance is the result of a large fracture zone encountered between 210 and 260 meters, which was not successfully grouted. Successive loggings over periods of several months showed these drifts to be always present above 280 meters, whereas temperatures in the bottom 22 meters were stable and could be consistently reproduced. Thus the bottom 22 meters were used in the determination of $Q$ and $Q^{*}$. It is believed that the temperatures in this interval reliably represent the undisturbed gradient. However, because of the small depth range used, this measurement of heat flow must be considered one of the more uncertain of our determinations, although it is better than the determinations for SB-5, DH-15, and LH-3.

The result for $Q^{*}$ of 1.7 calculated for HO-1 can be compared with the value of 1.3 obtained by Benfield [1947] on the west side of the Great Valley and the value of 1.2 reported by Roy et al. [1967] $30 \mathrm{~km}$ to the west. Accepting these data at face value, it would appear that there is a high heat flow in the vicinity of the fault.

\section{Discussion}

It was the intent of this investigation to determine whether or not heat generated by friction along a strike-slip fault, such as the San Andreas, was observable in the form of a heatflow anomaly in the vicinity of the fault trace. Knowledge of the magnitude of frictional heat generation would be helpful in the analysis of frictional stresses, fault geometry, and long-term rates of motion along the fault.

It is not obvious whether a detectable anomaly should exist near the fault. Energy is released in the neighborhood of a fault primarily in the form of radiated seismic waves and locally generated heat. The energy converted to heat is a function of the local nature of stresses and rates of strain in the fault region, which are not known in detail for any major fault from direct observation. The rate of production of heat calculated from the existing fault data is very model-dependent and is essentially unknown. On the other hand, the amount of energy radiated as seismic waves can be calculated from energy-magnitude relationships [Gutenberg and Richter, 1956] and the frequency of occurrence of earthquakes.

The relationship between the relative amounts of energy radiated as seismic waves and the heat energy dissipated locally, which would permit a direct comparison of seismic and heat energies, is not known, and attempts to relate the two have so far provided only speculative results [King and Knopoff, 1968].

A simple approach to estimating the amount of heat produced is to assume that the amount of energy converted to heat in the neighborhood of the fault is equal to the average amount of energy radiated as elastic waves. The assumption of equipartition of seismic and heat energies (on the average) is in no way self-evident. Large earthquakes dominate the seismic-energy release over long periods of time, and it has been suggested by King and Knopoff [1968] that for large-magnitude events a greater fraction of the stored strain energy that is released goes into seismic waves than is the case for smaller events. Therefore our estimate based on an assumed equipartition of energy may be high. However, it should also be noted that fault motion without accompanying seismic-energy release occurs in the form of creep. Creep has been shown to be responsible for significant amounts of fault offset along most branches of the San Andreas fault system [Whitten, 1955; Meade, 1963; Steinbrugge et al., 1960]. Creep is intrinsically a dissipative process, and this energy release should be entirely converted to heat in the vicinity of the fault trace. Thus our estimates of heat production based on equipartition of energy would be valid (within a factor of 2) in regions with a longterm history of creep, provided that stresses and average rates of displacement were equivalent to those in seismically active regions. It is not clear which portions of the fault have had a longterm history of creep and which have been seismically active; perhaps either type of fault activity can be predominant along a given segment of fault at a given time.

If we use the Gutenberg-Richter relationship,

$$
\log _{10} E=11.8+1.5 M
$$

and assuming that on the average two earthquakes of magnitude $M 8.3$ occur per century along the $800-\mathrm{km}$ length of the San Andreas fault (on the basis of the two known such events in the last 100 years), it follows from (2) that 
a heat production of $\sim 0.3 \mathrm{cal} / \mathrm{sec} / \mathrm{cm}$ of fault length of energy is produced, assuming equipartition. It will be shown that this can result in an observable heat-flow anomaly for favorable fault geometry. For this reason, we consider some theoretical models of heat production along faults in terms of line, strip, and volume sources. Details can be found in Henyey [1968].

\section{Line Source}

The temperature distribution after a time $t$ in a semi-infinite solid of diffusivity $\kappa$, with its surface $x=0 \mathrm{kept}$ at zero temperature and heated by a line source through the point $\left(x^{\prime}, y^{\prime}\right)$ and parallel to the surface, is given by equation 7 of Carslaw and Jaeger [1959, p. 262]. The flux at $x=0$ at a distance $y$ from the surface projection of the line source is given by

$$
\begin{aligned}
Q=\left.k \frac{\partial T}{\partial x}\right|_{x=0}=\frac{\epsilon}{\pi} & \frac{x^{\prime}}{x^{\prime 2}+\left(y-y^{\prime}\right)^{2}} \\
& \cdot \exp -\left[\frac{x^{\prime 2}+\left(y-y^{\prime}\right)^{2}}{4 \kappa t}\right]
\end{aligned}
$$

where $k$ is the thermal conductivity and $\epsilon$ is the energy liberated per unit time per unit length. In the case of a fault, $\epsilon$ will be the energy liberated per unit time per unit fault length. Hereafter we shall consider this to be the definition of $\epsilon$, and all source distributions will be normalized so as to give the same value of $\epsilon$. The steady-state flux (i.e., $t \rightarrow \infty$ ) is given by

$$
Q_{0}=\frac{\epsilon}{\pi} \frac{x^{\prime}}{x^{\prime 2}+\left(y-y^{\prime}\right)^{2}}
$$

\section{STrIP SoURCE}

Strip sources can be treated as a superposition in space of sources of the type given by equation 3. For a strip source $h_{0} \leqq x^{\prime} \leqq h_{1}$, where $y^{\prime}=0$, we have the steady-state surface flux given by

$$
Q_{0}=\frac{1}{\pi} \int_{h_{0}}^{h_{\mathrm{z}}} \sigma\left(x^{\prime}\right) \frac{x^{\prime}}{x^{\prime 2}+y^{2}} d x^{\prime}
$$

where $\sigma\left(x^{\prime}\right)$ is the energy liberated per unit time per unit area on the strip. From (4a) we have

$$
Q_{0}=\frac{\epsilon}{2 \pi\left(h_{1}-h_{0}\right)} \ln \left[\frac{y^{2}+h_{1}{ }^{2}}{y^{2}+{h_{0}}^{2}}\right]
$$

for

$$
\begin{array}{ll}
\sigma\left(x^{\prime}\right)=\sigma & h_{0} \leq x^{\prime} \leq h_{1} \\
\sigma\left(x^{\prime}\right)=0 & x^{\prime}<h_{0} \quad \text { and } \quad x^{\prime}>h_{1}
\end{array}
$$

(i.e., uniform source distribution)

and

$$
\begin{aligned}
Q_{0}= & \frac{\epsilon}{\pi\left(h_{1}-h_{0}\right)^{2}} \\
& \cdot\left\{h_{1}-h_{0}+y\left[\tan ^{-1} \frac{h_{0}}{y}-\tan ^{-1} \frac{h_{1}}{y}\right]\right\}
\end{aligned}
$$

for

$$
\begin{array}{ll}
\sigma\left(x^{\prime}\right)=A\left(x^{\prime}-h_{0}\right) & h_{0} \leq x^{\prime} \leq h_{1} \\
\sigma\left(x^{\prime}\right)=0 & x^{\prime}<h_{0} \text { and } x^{\prime}>h_{1}
\end{array}
$$

(i.e., sources linear function of depth)

$\sigma$ and $A$ do not appear owing to normalization (see above).

\section{Volume Source}

For a volume source $h_{0} \leq x^{\prime} \leq h_{1},\left|y^{\prime}\right| \leq a$, we have

$Q_{0}=\frac{1}{\pi} \int_{-a}^{a} \int_{h_{a}}^{h_{1}} \omega\left(x^{\prime}\right) \frac{x^{\prime}}{x^{\prime 2}+\left(y-y^{\prime}\right)^{2}} d x^{\prime} d y^{\prime}$

where $\omega\left(x^{\prime}\right)$ is the energy liberated per unit time per unit volume. This integration is simplified if the integration is carried out with respect to the $y^{\prime}$ variable first. From $(5 a)$ we get

$$
\begin{aligned}
& Q_{0}=\frac{\epsilon}{2 a \pi\left(h_{1}-h_{0}\right)} \\
& \cdot\left\{h_{1}\left[\tan ^{-1} \frac{a-y}{h_{1}}+\tan ^{-1} \frac{a+y}{h_{1}}\right]\right. \\
&+ \frac{a-y}{2} \ln \left[1+\frac{h_{1}{ }^{2}}{(a-y)^{2}}\right] \\
&+ \frac{a+y}{2} \ln \left[1+\frac{h_{1}{ }^{2}}{(a+y)^{2}}\right] \\
&- h_{0}\left[\tan { }^{-1} \frac{a-y}{h_{0}}+\tan ^{-1} \frac{a+y}{h_{0}}\right] \\
&- \frac{a-y}{2} \ln \left[1+\frac{h_{0}{ }^{2}}{(a-y)^{2}}\right] \\
&\left.-\frac{a+y}{2} \ln \left[1+\frac{h_{0}{ }^{2}}{(a+y)^{2}}\right]\right\}
\end{aligned}
$$


for

$$
\begin{aligned}
\omega\left(x^{\prime}\right)= & \omega \quad h_{0} \leq x^{\prime} \leq h_{1} \\
\omega\left(x^{\prime}\right)= & 0 \quad x^{\prime}<h_{0} \quad \text { and } \quad x^{\prime}>h_{1} \\
& \text { (i.e., uniform distribution) }
\end{aligned}
$$

and

$$
\begin{aligned}
Q_{0} & =\frac{\epsilon}{2 a \pi\left(h_{1}-h_{0}\right)^{2}} \\
& \cdot\left\{\left[h_{1}{ }^{2}+(a+y)^{2}\right] \tan ^{-1} \frac{a+y}{h_{1}}\right. \\
+ & {\left[{h_{1}}^{2}+(a-y)^{2}\right] \tan ^{-1} \frac{a-y}{h_{1}}+2 a h_{1} } \\
& -\left[{h_{0}}^{2}+(a+y)^{2}\right] \tan ^{-1} \frac{a+y}{h_{0}} \\
& \left.-\left[h_{0}{ }^{2}+(a-y)^{2}\right] \tan ^{-1} \frac{a-y}{h_{0}}-2 a h_{0}\right\}
\end{aligned}
$$

for

$$
\begin{aligned}
& \omega\left(x^{\prime}\right)=A\left(x^{\prime}-h_{0}\right) \quad h_{0} \leq x^{\prime} \leq h_{1} \\
& \omega\left(x^{\prime}\right)=0 \quad x^{\prime}<h_{0} \text { and } x^{\prime}>h_{1} \\
& \text { (i.e., linear function of depth) }
\end{aligned}
$$

It is important to note that in relation (4b)

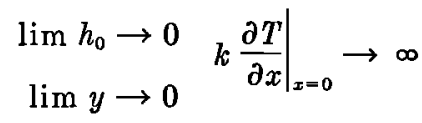

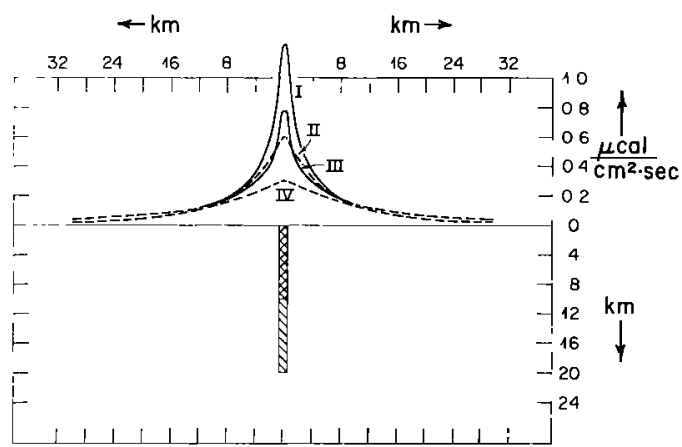

Fig. 6. Surface heat flow due to a $1-\mathrm{km}$-wide fault zone generating heat at the rate of $1 \mathrm{cal} / \mathrm{sec} / \mathrm{cm}$ of fault length. Case 1, fault zone $10 \mathrm{~km}$ deep, uniform source distribution; case 2, fault zone $10 \mathrm{~km}$ deep, sources distributed linearly with depth; case 3, fault zone $20 \mathrm{~km}$ deep, uniform source distribution; case 4, fault zone $20 \mathrm{~km}$ deep, sources distributed linearly with depth.

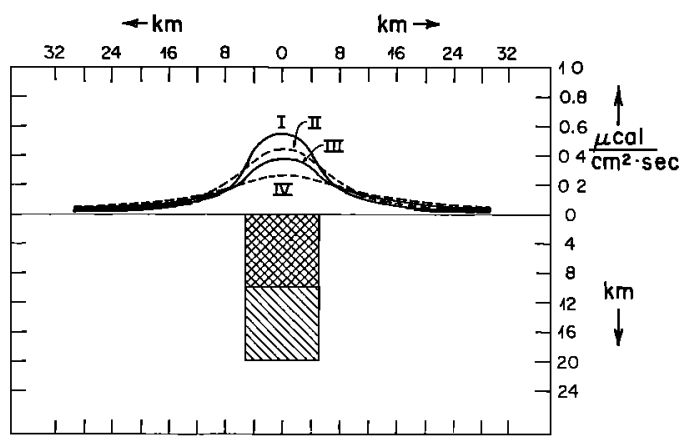

Fig. 7. Surface heat flow due to a $10-\mathrm{km}$-wide fault zone generating heat at the rate of $1 \mathrm{cal} / \mathrm{sec} / \mathrm{cm}$ of fault length. Case 1, fault zone $10 \mathrm{~km}$ deep, uniform source distribution; case 2, fault zone $10 \mathrm{~km}$ deep, sources distributed linearly with depth; case 3, fault zone $20 \mathrm{~km}$ deep, uniform source distribution; case 4, fault zone $20 \mathrm{~km}$ deep, sources distributed linearly with depth.

with similar behavior existing for the line source. However, for strip sources having linear-withdepth source distributions and for any volume source, these conditions do not arise.

Plots of relations $5 b$ and $5 c$ are given in Figures 6 and 7 for fault widths of 1 and $10 \mathrm{~km}$, respectively, assuming $h_{0}=0$. All cases have been normalized to a total heat production (i.e., value of $\epsilon$ ) of $1 \mathrm{cal} / \mathrm{sec} / \mathrm{cm}$ of fault length. For other rates of heat production, the ordinate can be linearly scaled by the appropriate factor.

Four cases of source geometry are shown for the $1-\mathrm{km}$-wide fault zone in Figure 6, and the same four cases are also shown for the $10-\mathrm{km}$ wide fault zone in Figure 7. They are (1) a 10-km-deep fault zone having a uniform source distribution, (2) a 10-km-deep fault zone having a linear-with-depth distribution, (3) a $20-\mathrm{km}$ deep fault zone having a uniform distribution, and (4) a $20-\mathrm{km}$-deep fault zone having a linearwith-depth distribution.

Comparison of Figures 6 and 7 shows that a narrow fault zone considerably enhances the peak values. A $10-\mathbf{k m}$-deep fault zone that is 1 $\mathrm{km}$ wide and has a uniform source distribution will have a maximum approximately twice that of a fault zone that is $10 \mathrm{~km}$ wide. Furthermore, the narrow fault zones confine the anomaly to a central fault trace and therefore, if in reality it is so confined, the fault-generated anomaly would be less likely to be tied up with regional noise. It can be seen from Figures 6 and 7 that the 
half-width for a 1-km-wide fault zone with uniform heat production is about $4 \mathrm{~km}$, whereas for a $10-\mathrm{km}$-wide zone it is of the order of $10 \mathrm{~km}$.

It might be argued that the fault should be represented by a strip source of the type given by equation $4 b$, rather than by a volume source. However, a discussion of the anomaly maximum becomes ambiguous if sources are permitted to approach the surface $x=0$. In the limiting case of any portion of the heat produced at the surface, the peak would be infinitely high. The flanks of the $1-\mathrm{km}$-wide volume source, i.e., at distances greater than, say, $0.5 \mathrm{~km}$ from the center of the fault zone, behave like the strip source, and we argue that this is a logical presentation of the problem.

Figures 6 and 7 also show, for the fault geometries just discussed, the anomalies expected for linear-with-depth source distributions. This type of source distribution can be assumed to result if fault friction is a function of hydrostatic pressure down to a characteristic depth of the order of $20 \mathrm{~km}$. Heat that is produced below this depth will appear in the form of a broad anomaly, the shape of which cannot be described with the present restricted distribution of hole locations. Figure 6 shows that if we distribute linearly with depth the same quantity of sources considered for the uniform distribution in a 1-km-wide fault zone, the anomaly maximum is reduced by a factor of 2. For wider fault zones (Figure 7) the effect is less marked.

In summary, it can be concluded that, within reasonable limits, although an anomaly is significantly enhanced by a narrow source distribution, for a fault zone of a given depth the distribution of sources within the zone does not appreciably change the peak magnitude of the anomaly. Factors of the order of 2,3 , and 4 (not 10) are involved-the same factors involved in the uncertainty of earthquake energy-magnitude relations and the recurrence rates for large-magnitude events.

Consideration of the curves in Figures 6 and 7, which were determined for a rate of heat production along the fault of $1 \mathrm{cal} / \mathrm{sec} / \mathrm{cm}$ of fault, allows us to set detectability limits for actual rates of heat production for the different fault geometries. These limits are controlled by the intrinsic variability of heat-flow measurements. Differences in heat flow on the order of $0.1 \mu \mathrm{cal} /$ $\mathrm{cm}^{2} / \mathrm{sec}$ or less cannot be considered significant and must be attributed to the multitude of unknown factors such as variations in local radioactivity, topography, and lateral variations in conductivity. The experimental precision of a single heat-flow measurement is also generally no better than this figure when corrected for topography, and it may be considerably worse in regions of high relief. Thus we suggest for the purpose of this discussion that an anomaly must be of the order of $0.3 \mu \mathrm{cal} / \mathrm{cm}^{2} / \mathrm{sec}$ or larger to be detectable in a nonstatistical manner, as is the case for the relatively few number of heat-flow measurements that are presented here. On these grounds, all the anomalies in Figures 6 and 7 should be observable, with perhaps the exception of curve 4 in Figure 7. If the rate of heat production along the fault is reduced by a factor of 3 to $\sim 0.3 \mathrm{cal} / \mathrm{sec} / \mathrm{cm}$ of fault, only anomalies 1 and 2 in Figure 6 would be observable. Hence we can reasonably conclude that if we are to observe a heat-flow anomaly in the neighborhood of a fault under the constraint of a reasonable fault geometry (i.e., reasonable distribution of sources), the fault must be producing heat (to a depth, assumed here, of about $20 \mathrm{~km}$ ) at a rate at least as great as $0.3 \mathrm{cal} / \mathrm{sec} / \mathrm{cm}$ of fault length.

\section{SuMmary}

Figure 8 shows a plot of the corrected heat flow $Q^{*}$ at each drill hole versus distance in kilometers along a normal to the nearest major strike-slip fault. Some arbitrariness is involved in the plotting on each profile, especially since all holes do not generally lie in a linear array. For example, the value reported by Benfield [1947] is plotted on the Hollister profile, although the hole is located about $100 \mathrm{~km}$ southeast of the Hollister region. Also shown on the Anza profile is a regional value of heat flow reported by Rex [1966; also personal communication, 1971] for the Imperial Valley region south of the Salton Sea.

The heat-flow data from three of the profiles, Hollister, Tehachapi Mountains, and Anza, show some degree of correlation with distance from the fault. The Lake Hughes and San Bernardino Mountains profiles show no correlation of heat flow with distance from the fault. Thus, if we are to believe that the data are representative of the heat flow at each locality, the correlation of heat flow with the fault for only certain 
profiles suggests that either (1) there are marked differences in the nature of faulting for different portions of the fault, or (2) the high heat-flow values must be related to other geologic or topographic effects, or both, in the neighborhood of the fault.

From consideration of Figure 8, we can attribute up to $0.5 \mu \mathrm{cal} / \mathrm{cm}^{2} / \mathrm{sec}$ to excess heat flow in the neighborhood of the fault at these localities along the San Andreas fault system. We have shown that under favorable conditions this anomaly can be produced by a rate of heat production approximately equivalent to that involved in the release of seismic waves along the fault. This would suggest that faults have a seismic efficiency (i.e., ratio of seismic energy release to total energy release) of the order of $50 \%$, with a high degree of confidence that this efficiency factor is at least as great as $10 \%$. If we attribute a portion or all of the excess flux to faulting, we must offer an explanation as to what is atypical about the Lake Hughes and San Bernardino profiles. It has been suggested by Allen [1968] that the San Andreas fault may be subdivided into portions having different types of seismic activity. That portion of the fault between Lake Hughes and San Bernardino appears to be 'locked' into place, experiencing very little seismic activity and virtually no microseismic or creep activity. It is assumed [Allen et al., 1965] that strain energy accumulating in this region is released by relatively infrequent large-magnitude earthquakes. Thus, if large events are more seismically efficient than small events, as suggested by King and Knopoff [1968], we would expect no excess heat flow along this segment of fault.

On the other hand, we cannot rule out the possibility that the observed differences in heat flow are the result of the natural variability of heat-flow measurements. Unknown topographic, refractive, radioactive, and climatic effects can account for apparent anomalies as large as those we have observed. Because of the rugged topography and erratic geology in the neighborhood of the major strike-slip faults in California, these factors cannot be ruled out as potential sources of anomalous heat flow at the locations investigated. For example, Henyey [1968] has suggested that $50 \%$ or more of the Tehachapi Mountains profile anomaly can be explained by a combination of these factors, resulting in large part from a major lithologic discontinuity across the Garlock fault, as shown in Figure 2 (see also the appendix). Thus only about $0.3 \mu \mathrm{cal} / \mathrm{cm}^{2} / \mathrm{sec}$ remains unexplained. Similarly, the increase in heat flow from $\mathrm{AN}-2$ toward $\mathrm{AN}-1$ and $\mathrm{AN}-3$ (Anza profile) may be related to a transition from low heat flow in the Peninsular Range province (see Figure 8) to high heat flow in the Imperial Valley, as suggested by Rex's [1966] data. Until such time as a more complete profile is obtained, particularly including holes to the east of the San Jacinto fault in this region, this interpretation must be regarded as only speculative. A similar transition has been noted by Roy et al. [1968] for the transition between the Sierra Nevada and Basin and Range provinces.

It should be emphasized that the apparent lack of a well-defined heat-flow anomaly near large strike-slip faults does not preclude the possibility that such anomalies are now generating significant amounts of heat. First, the high density of such faults in California, especially south of the Tehachapi Mountains, may contribute to a regional high in the heat flow that cannot be easily distinguished from contributions due to other sources; that is, we are not able to identify 'base levels' of heat flow with respect to heat generation along faults. Second, thermal equilibrium may not have been reached if these faults have been active for only the last few million years; we would thus be observing only a fraction of the energy released.

The average value of the seventeen heatflow determinations reported here, taken without regard to the nature of heat production, is 1.65 $\mu \mathrm{cal} / \mathrm{cm}^{2} / \mathrm{sec}, \pm 0.28$ s.d. Figure 9 shows a comparison of these data with other nearby measurements in California-Nevada and offshore. This average value is somewhat greater than the stable continental average of about $1.2 \mu \mathrm{cal} /$ $\mathrm{cm}^{2} / \mathrm{sec}$; however, it is significantly less than the average value of $2.0 \mu \mathrm{cal} / \mathrm{cm}^{2} / \mathrm{sec}$ or greater for the nearby Basin and Range province. Thus, assuming that heat due to radioactivity or faulting or other factors, or to a combination of factors, will not change these relative heat-flow averages, it can be assumed that the continental margin of California is underlain by a crust and upper mantle whose thermal characteristics are intermediate between those of stable, pre-Mesozoic continental regions and the thermally active, 
Heat Flow near Major Strike-Slip Faults

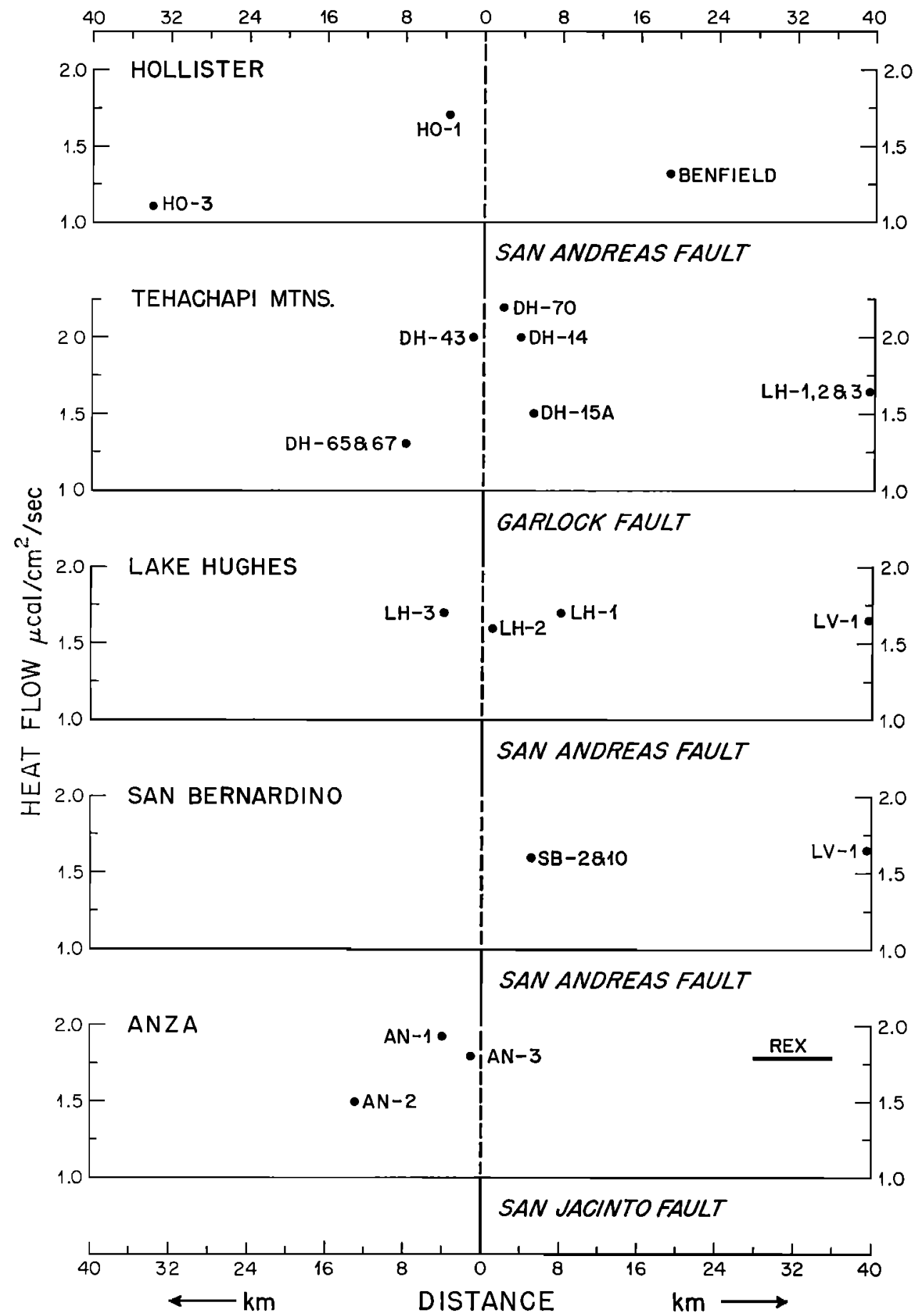

Fig. 8. Drill-hole heat-flow data plotted versus distance from nearest major strike-slip fault for five regions investigated. 
Mesozoic-Cenozoic orogenic belts, such as the Basin and Range and mid-ocean ridge systems. More importantly, however, the data shown in Figure 9, together with other heat-flow data (not shown) from the continental margins of western North America, may reflect the Neogene tectonic history of this region, since the time scales for both crustal-thermal and Neogene tectonic processes are about the same.

\section{APPENDIX}

Refraction at a vertical interface. Heat-flow measurements made near a vertical contact between lithologies having a conductivity contrast will have apparently higher or lower heat flows, depending on which side of the contact they are on, because of refraction across the interface. This situation occurs across the Garlock fault, where there is approximately a $20 \%$ conductivity contrast across the north branch of the fault. A first approximation to the effect can be obtained from a crude physical model and simple boundary-value problem whose solution is given by Carslaw and Jaeger [1959, section 16.4]. Con-

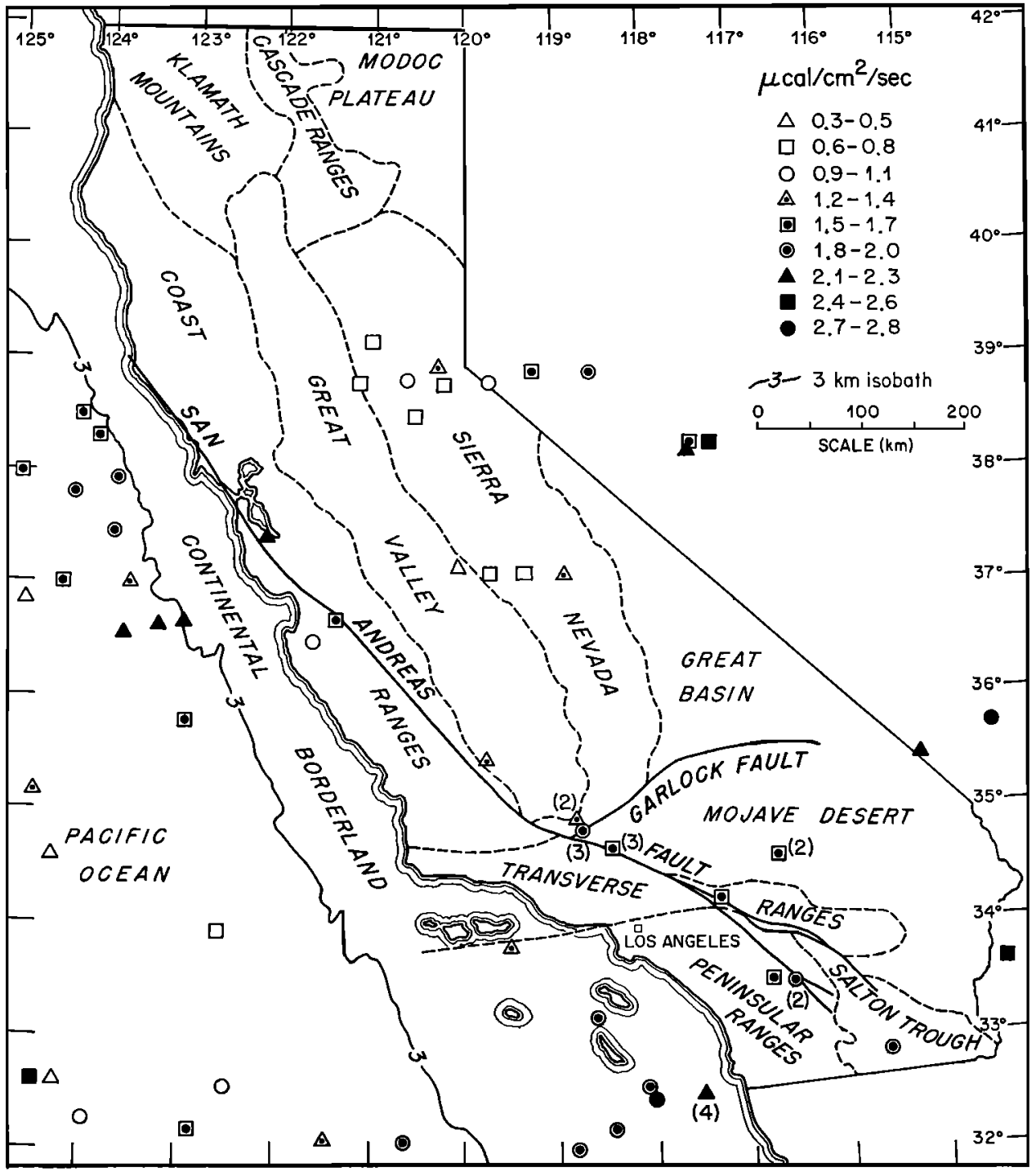

Fig. 9. Locations of published heat-flow data in and around California. 
Heat Flow near Major Strike-Slip Faults

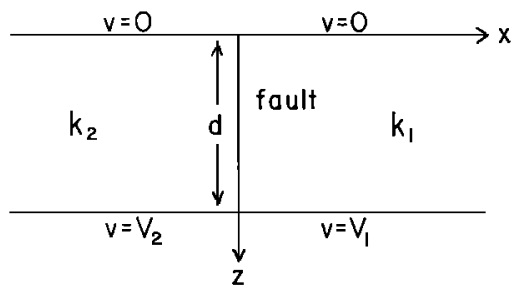

Fig. 10. Thermal geometry for refraction at vertical interface (fault) between two media of conductivities $k_{1}$ and $k_{2}$.

sider the composite infinite slab $0<z<d$, of which $x>0$ is of conductivity $k_{1}$ and $x<0$ is of conductivity $k_{2}$, with the boundary conditions (Figure 10)

$$
\begin{array}{cccc}
v=0 & z=0 & -\infty<x<\infty \\
v=V_{1} & z=d & x>0 \\
v=V_{2} & z=d & x<0
\end{array}
$$

where $v$ is the temperature; then if $V_{1}$ and $V_{2}$ are the temperatures for $x>0$ and $x<0$, respectively, the flux at the surface is given by

$$
\begin{array}{r}
\left.k_{1} \frac{\partial v}{\partial z}\right|_{z=0}=\frac{k_{1} V_{1}}{d}-\frac{2 k_{1} k_{2}\left(V_{2}-V_{1}\right)}{d\left(k_{1}+k_{2}\right)} \\
\cdot \sum_{n=1}^{\infty}(-1)^{n} e^{-n \pi x / d} \quad x>0 \\
\left.k_{2} \frac{\partial v}{\partial z}\right|_{z=0}=\frac{k_{2} V_{2}}{d}+\frac{2 k_{1} k_{2}\left(V_{2}-V_{1}\right)}{d\left(k_{1}+k_{2}\right)} \\
\cdot \sum_{n=1}^{\infty}(-1)^{n} e^{n \pi x / d} \quad x<0
\end{array}
$$

Now let us take $k_{1}=6.9 \mathrm{mcal} / \mathrm{cm} \mathrm{sec}{ }^{\circ} \mathrm{C}$ and $k_{2}=8.3 \mathrm{mcal} / \mathrm{cm}$ sec ${ }^{\circ} \mathrm{C}$. If we assume that the plutons extend to a depth of $10 \mathrm{~km}$, we set $d=10 \mathrm{~km}$. Let us arbitrarily set $V_{1}=200^{\circ} \mathrm{C}$ on the basis of a $20^{\circ} \mathrm{C} / \mathrm{km}$ gradient, then if we make the assumption that the fluxes from below $10 \mathrm{~km}$ into both plutons are equivalent as $|x| \rightarrow \infty$, we have

$$
k_{1} V_{1}=k_{2} V_{2}
$$

or

$$
V_{2}=k_{1} V_{1} / k_{2} \simeq 166^{\circ} \mathrm{C}
$$

Putting these numerical values into (A1), we have

$$
\begin{aligned}
& \left.k_{1} \frac{\partial v}{\partial z}\right|_{z=0}=q_{1}=1.38 \\
& +0.256 \sum_{n=1}^{\infty}(-1)^{n} e^{-n \pi x / 10} \quad x>0 \\
& \left.k_{2} \frac{\partial v}{\partial z}\right|_{z=0}=q_{2}=1.38 \\
& -0.256 \sum_{n=1}^{\infty}(-1)^{n} e^{n \pi x / 10} \quad x<0
\end{aligned}
$$

Now

$$
\begin{aligned}
& {\left[\begin{array}{ll}
\sum_{n=1}^{\infty}(-1)^{n} e^{-n \pi x / 10} & x>0
\end{array}\right]} \\
& =\left[\begin{array}{ll}
\sum_{n=1}^{\infty}(-1)^{n} e^{n \pi x / 10} & x<0
\end{array}\right] \\
& \sum_{n=1}^{\infty}(-1)^{n} e^{-n \pi x / 10} \cong-0.43 \text { for } x=1 \mathrm{~km} \\
& \sum_{n=1}^{\infty}(-1)^{n} e^{-n \pi x / 10} \cong-0.28 \text { for } x=3 \mathrm{~km} \\
& \sum_{n=1}^{\infty}(-1)^{n} e^{-n \pi x / 10} \cong-0.04 \text { for } x=10 \mathrm{~km}
\end{aligned}
$$

Putting these into (A2), we get

$$
\begin{array}{cc}
q_{1}=1.49 \mathrm{HFU} & q_{2}=1.27 \mathrm{HFU} \\
& \text { for }|x|=1 \mathrm{~km} \\
q_{1}=1.45 \mathrm{HFU} & q_{2}=1.31 \mathrm{HFU} \\
& \text { for }|x|=3 \mathrm{~km} \\
q_{1}=1.39 \mathrm{HFU} & q_{2}=1.37 \mathrm{HFU} \\
& \text { for }|x|=10 \mathrm{~km}
\end{array}
$$

Thus a $20 \%$ change in conductivity produces an apparent $17 \%$ difference in heat flow at locations $1 \mathrm{~km}$ on either side of the discontinuity, an $11 \%$ difference at $3 \mathrm{~km}$, and at $10 \mathrm{~km}$, i.e., $\sim d$, the effect is down to about $1.5 \%$.

Acknowledgments. We would like to acknowledge helpful discussions with R. F. Roy, D. D. Blackwell, J. N. Brune, R. V. Sharp, and L. T. Silver. Field and laboratory assistance during various phases of the work was provided by $H$. T. Baldwin, C. Chase, and L. Soderblom. The California Department of Water Resources (R. Bisio, in particular) and the Southern Pacific Land Company kindly provided access to several of the drill holes used in this work. 
The research and drilling operations were supported by National Science Foundation grant GP3412.

\section{REFERENCES}

Allen, C. R., The tectonic environments of seismically active and inactive areas along the San Andreas fault system, in Proceedings of the Conference on Geologic Problems of the San Andreas Fault System, vol. 11, edited by W. R. Dickinson and A. Grantz, pp. 70-82, Stanford Univ. Publ., Geol. Sci., Stanford, Calif., 1968.

Allen, C. R., P. St. Amand, C. F. Richter, and J. M. Nordquist, Relationship between seismicity and geologic structure in the southern California region, Bull. Seismol. Soc. Amer., 55, 753-797, 1965.

Atwater, T., Implications of plate tectonies for the Cenozoic tectonic evolution of western North America, Geol. Soc. Amer. Bull., 81, 3513-3536, 1970.

Bailey, T. L., and R. H. Jahns, Geology of the Transverse Range province, southern California, Calif. Div. Mines Geol., Bull., 170, 83-106, 1954.

Benfield, A. E., A heat flow value for a well in California, Amer. J. Sci., 245, 1-18, 1947.

Birch, F., Flow of heat in the Front Range, Colorado, Geol. Soc. Amer. Bull., 61, 567-630, 1950.

Bullard, E. C., The earth's interior, in The Solar System, vol. 2, The Earth as a Planet, edited by G. Kuiper, 751 pp., Univ. Chicago Press, Chicago, Ill., 1954 .

California Department of Water Resources Bulletin, 119-2, 1964.

Carslaw, H. S., and J. C. Jaeger, Conduction of Heat in Solids, 497 pp., Oxford University Press, London, 1959.

Clark, S. P., Heat flow at Grass Valley, California, Eos Trans. AGU, 38, 239-244, 1957.

Dibblee, T. W., Jr., Geologic Map of the Bouquet Reservoir Quadrangle, Los Angeles Connty, California, U.S. Geol. Surv. Miner. Invest. Field Studies Map MF-79, 1961.

Dibblee, T. W., Jr., Geologic Map of the Lucerne Valley Quadrangle, San Bernardino County, California, U.S. Geol. Surv. Misc. Invest. Map I-426, 1964.

Gutenberg, B., and C. F. Richter, Earthquake magnitude, intensity, energy, and acceleration, Bull. Seismol. Soc. Amer., 46, 105-145, 1956.

Henyey, T. L., Heat flow near major strike-slip faults in central and southern California, Ph.D. thesis, Calif. Inst. of Technol., Pasadena, 1968.

Henyey, T. L., G. J. Wasserburg, and R. F. Roy, Heat flow near major faults in central and southern California (abstract), Geol. Soc. Amer. Annu. Meet. New Orleans, 1967.

Jaeger, J. C., The effect of the drilling fluid on temperatures measured in boreholes, $J$. Geophys. Res., 66, 563-569, 1961.

Jaeger, J. C., and A. Beck, The calculation of heat flow through disks and its application to conductivity measurements, Brit. J. Appl. Phys., 6, 15-16, 1955.
King, C., and L. Knopoff, Stress drop in earthquakes, Bull. Seismol. Soc. Amer., 58, 249-257, 1968.

Lachenbruch, A. H., Preliminary geothermal model of the Sierra Nevada, J. Geophys. Res., 73, 6977$6989,1968$.

McKenzie, D. P., and W. J. Morgan, Evolution of triple junctions, Nature, 224, 125-133, 1969.

Meade, B. K., Horizontal erustal movements in the United States, in Report to Committee on Recent Crustal Movements, Int. Union Geod. Geophys. Gen. Assem., Berkeley, Calif., 25 pp., U.S. Coast and Geod. Surv., 1963.

Meade, B. K., and J. B. Small, Current and Recent movement on the San Andreas fault, Calif. Div. Mines Geol., Bull., 190, 385-391, 1966.

Oakeshott, G. B., San Andreas fault in the California Coast Ranges province, Calif. Div. Mines Geol., Bull., 190, 357-373, 1966.

Orowan, E., Mechanism of seismic faulting, in Rock Deformation, Mem. 79, edited by David Griggs and John Handin, pp., 323-345, Geological Society of America, Boulder, Colo., 1960.

Ratcliffe, E. H., Conductivity of fused and crystalline quartz, Brit. J. Appl. Phys., 10, 22-25, 1959.

Rex, R. W., Heat flow in the Imperial Valley of California (abstract), Eos Trans. AGU, 4\%, 181, 1966.

Roy, R. F., Heat flow measurements in the United States, Ph.D. thesis, Harvard University, Cambridge, Mass., 1963.

Roy, R. F., J. N. Brune, T. L. Henyey, and G. J. Wasserburg, Heat flow in a zone of high creep rate along the San Andreas fault, California (abstract), Eos Trans. AGU, 48, 209, 1967.

Roy, R. F., D. D. Blackwell, E. R. Decker, and F. Birch, Heat flow in the United States, J. Geophys. Res., 79, 5207-5221, 1968.

Sharp, R. V., Geology of the San Jacinto fault zone in the Peninsular Ranges of southern California, Geol. Soc. Amer. Bull., 78, 705-729, 1967.

Smith, G. I., Time of last displacement on the middle part of the Garlock fault, California, U.S. Geol. Surv. Prof. Pap. 400-B, 280, 1960.

Stearns, N. D., H. T. Stearns, and G. A. Waring, Thermal springs in the United States, U.S. Geol. Surv. Water Supply Pap. 679-B, 59-191, 1937.

Steinbrügge, K. V., E. G. Zacher, D. Tocher, C. A. Whitten, and C. N. Claire, Creep on the San Andreas fault, Bull. Seismol. Soc. Amer., 50, $389-415,1960$.

Wasserburg, G. J., R. Kovach, T. L. Henyey, and R. F. Roy, Heat flow in the vicinity of the San Andreas fault (abstract), Eos Trans. $A G U, 47$, 181, 1966.

Whitten, C. A., Measurements of earth movements in California, Calif. Div. Mines Geol., Bull., 171, 75-80, 1955.

Wiese, J. H., Geology and mineral resources of the Neenach quadrangle, California, Calif. Div. Mines Geol., Bull., 153, 51 pp., 1950.

(Received November 9, 1970; revised August 16, 1971.) 